\title{
Performance optimization of polymeric porous membrane-based liquid desiccant air dehumidifier used in air conditioning system
}

\author{
Ali Mohammad Jafarpour ${ }^{1} \cdot$ Farivar Fazelpour $^{1} \cdot$ Seyyed Abbas Mousavi ${ }^{2}$
}

Received: 16 July 2019 / Accepted: 24 October 2019 / Published online: 2 December 2019

(c) The Author(s) 2019

\begin{abstract}
In this study an experimental design was developed to optimize the performance and structure of a membrane-based parallelplate liquid desiccant dehumidifier used in air conditioning regeneration system which operates under high humidity weather conditions. We conducted a series of polymeric porous membranes with different compositions fabricated that were prepared with various weight percentages of polysulfone (PSU), mixed with $N$-methyl-2-pyrrolidone (NMP) and dimethyl form amide (DMF) solvents. Furthermore, the designed experiments were performed under various operating conditions, indicating that the dehumidification efficiency declines with increasing flow rate, temperature, and humidity. Consequently, a membrane with optimized porosity and moisture permeability was selected which resulted in eliminating the carryover of solution droplets in the air, largely due to separating the flow condition of liquid desiccant $(\mathrm{Li} \mathrm{Cl})$ and air. This specific design is also greatly benefited by removing the water vapor from the air stream. The results of mathematical model simulations indicate that the DMF solvent had higher dehumidification capability compared with that of NMP under the optimized operating conditions. Additionally, it can clarify the porosity of the membrane which plays a significant role in the overall performance. Therefore, the fabricated membrane produces fresh cool air, and it can be applied as a guiding sample for designing the membrane-based dehumidifier with improved performance.
\end{abstract}

Keywords Experimental design $\cdot$ Porous membranes $\cdot$ Dehumidifier $\cdot$ Air conditioning $\cdot$ Mass transfer

$\begin{array}{ll}\text { Abbreviations } \\ \mathrm{d} & \text { Channel height }(\mathrm{mm}) \\ \mathrm{D} & \text { Diffusivity }\left(\mathrm{m}^{2} / \mathrm{s}\right) \\ \mathrm{m} & \text { Mass flow rate }(\mathrm{kg} / \mathrm{s}) \\ \mathrm{k} & \text { Mass transfer coefficient }(\mathrm{m} / \mathrm{s}) \\ \mathrm{L} & \text { Contactor length }(\mathrm{m}) \\ \mathrm{m} & \text { Mass flow rate }(\mathrm{kg} / \mathrm{s}) \\ \mathrm{T} & \text { Temperature }(\mathrm{K}) \\ \mathrm{u} & \text { Velocity }(\mathrm{m} / \mathrm{s}) \\ \mathrm{W} & \text { Contactor width }(\mathrm{mm}) \\ \mathrm{X}, \mathrm{y}, \mathrm{z} & \text { Coordinates }(\mathrm{m}) \\ \mathrm{X} & \text { Mass fraction of water mass in solution mass }(\mathrm{kg} \\ & \text { water } / \mathrm{kg} \text { solution }) \\ Q_{\mathrm{br}} & \text { Mass source }\left(\mathrm{kg} /\left(\mathrm{m}^{3} \cdot \mathrm{s}\right)\right)\end{array}$

Farivar Fazelpour

f_fazelpour@azad.ac.ir

1 Department of Energy Systems Engineering, Faculty of Engineering, South Tehran Branch, Islamic Azad University, Tehran, Iran

2 Department of Chemical and Petroleum Engineering, Sharif University of Technology, Tehran, Iran

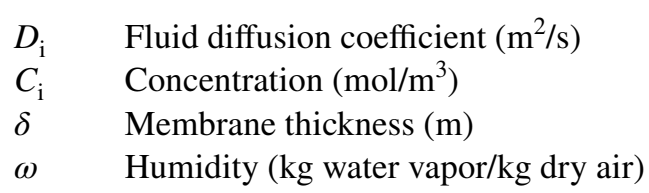

\begin{tabular}{ll}
\multicolumn{2}{l}{ Subscripts } \\
$a$ & Air \\
$e$ & Equilibrium \\
in & Inlet \\
$L_{\mathrm{at}}$ & Latent \\
mem & Membrane \\
out & Outlet \\
$R$ & Mass flow rate ratio \\
$s$ & Solution \\
$V_{\mathrm{a}}$ & Water vapor in the air \\
$W_{\mathrm{s}}$ & Water in solution
\end{tabular}

\section{Greek Symbols}

$\rho \quad$ Density $\left(\mathrm{kg} / \mathrm{m}^{3}\right)$

$\mu \quad$ Dynamic viscosity $(\mathrm{kg} /(\mathrm{m} \cdot \mathrm{s}))$

$\mathrm{P} \quad$ Pressure $(\mathrm{Pa})$

$\varepsilon_{\mathrm{p}} \quad$ Porosity

$K \quad$ Permeability tensor of the porous medium $\left(\mathrm{m}^{2}\right)$ 


\section{Introduction}

Growth in the world's population and economy, coupled with rapid urbanization, will result in a substantial increase in energy demand over the coming years, a vast part of which is significantly attributed to the energy consumed by buildings for air conditioning [1]. The desired energy for such a demanding requirement, particularly in humid climates, is provided by burning fossil fuels whose consumption leads to serious energy and environmental problems [2]. Additionally, short- or long-term exposure to air pollution has been associated with a wide range of human health effects. Hence, paying less attention to control measures that reduce fossil fuel consumption could result in human health hazards, discomfort, and productivity decline of human beings [3]. One factor that is also important to be considered is the climatic parameter such as relative humidity. It appears that effective control of humidity stands as a critical matter for maintaining a healthy indoor environment and reducing energy consumptions [4].

Recently, there have been a number of methods to reduce the amount of moisture in the air such as moisture condensing method, desiccant-wheel method, and liquid desiccant method which are considered as conventional air dehumidification procedures [5]. In comparison, the liquid desiccant method which utilizes liquid desiccant such as lithium chloride $(\mathrm{Li} \mathrm{Cl})$ [6], lithium bromide $(\mathrm{LiBr})$ [7], and magnesium chloride $\left(\mathrm{MgCl}_{2}\right)$ [8] for the adsorption of water vapor in air not only results in lower energy consumption, but also provides a faster and more efficient dehumidification due to its lower regeneration temperature compared to other methods [9]. The advantageous liquid desiccant method suffers from the issue of carryover of the liquid desiccant which could lead to the corrosion of operating components [10]. Therefore, it is essential to assess a method or promoter with lower energy consumption and higher regeneration efficiency in air conditioning systems [11].

Nowadays, the membrane-based liquid desiccant air dehumidification which had been mostly applied in wastewater treatment processes has become more interesting for researchers worldwide, who are investigating the field of air conditioning systems [12]. This technology, which is a thermally driven separation process, utilizes the vapor pressure difference across the porous membrane as a driving force to achieve successful separation and dehumidification [13]. The most important difference between this method and the conventional liquid desiccant air dehumidification is the utilization of semi-permeable membranes for the separation of the processing air and liquid desiccant fluids which generally results in the successful inhibition of liquid from penetrating [14]. Due to this phenomenon, the desiccant droplets cannot enter the air stream which further prevents the corrosion of the air conditioner components [15]. Moreover, this separation suppresses the carryover of liquids and the by-product gases of the operation [16]. As a result, this technology has various advantages compared to conventional air conditioning technologies such as (1) higher air dehumidification/purification capability [17], (2) pollution-free structure [18], (3) low energy consumption [19], (4) operability at lower temperatures $\left(40-80{ }^{\circ} \mathrm{C}\right)$ [20], and (5) negligible heat transfer through the membrane. It is clear that the production of membranes for improved and optimized structure and performance has become highly desirable.

The superior performance of polymeric membranes have been proved by the results obtained from the research work of Abdel-Salam et al., who reviewed the application, energy saving, and economic and environmental impact of liquid membrane energy exchangers. They demonstrated that in comparison to the conventional liquid desiccant systems, their energy consumption is reduced by 10-50\% [21]. Moreover, Baris Kavasogullari et al. designed and manufactured an eco-friendly liquid desiccant system, which is membrane contained polycarbonate boards considered as innovative packing material in an open-cycle calcium chloride-water system [22]. The proposed system had a higher surface tension compared to other conventional polymeric materials. In further investigation of obtaining more reliable results concerning the performance of the systems, Dec hang Wang et al. introduced a mathematical model that was experimentally validated for a system containing a hollow fiber membrane in its energy storage unit [23]. The project performed by Hongyu Bai et al. was also attributed to the evaluation of the performance of a membrane-based dehumidifier applying an experimental design with a datasheet of operating parameters and their corresponding impacts on the operation [24]. The results indicated that the efficacy of the humidifier increased by increasing the flow rate ratio of the solution to air, but decreased by increasing the operating temperature.

Based on our literature review, the production of membranes with improved and optimized structure and performance has the ability to reduce energy consumption and component corrosion remarkably. However, there are a limited number of studies investigating the impact of the operating conditions and the factors governing the fabrication of membranes on the performance of the dehumidifier that is based on designing a reliable experimental method. Thus, we decided to conduct a research project to primarily optimize the system performance that could also be qualified as a role model for future production. This goal can be achieved by evaluating the control factors with experimental design and perform mathematical model simulations. 
The objective of this paper is to establish an experimental design for the mathematical simulation of factors governing the structure and performance of porous membranes that are used in the dehumidification of air conditioning systems with improved performance in energy use and environmental impact. Firstly, the structure and performance of the fabricated membrane were designed and then the reasons governing such a capability for avoiding the carryover and corrosion problems were discussed. The reliability of the model was further evaluated using COMSOL. Overall, the system application along with the obtained results was used to provide support for the capability of the fabricated membrane in solution desiccant air conditioning systems, especially in humid areas.

\section{Methodology}

The conventional experiments with one variable at a time were applied as an experimental design to optimize the structure and the performance of the membranes in air conditioners. This procedure was highly beneficial for minimizing the variance associated with the estimates of the models with fewer experimental runs. According to the results reported in the literature, the porosity of the membranes, polymer additives, humidity, temperature, and the flow rate are the most important factors governing the performance of the air conditioner. Therefore, the levels of 15, 17.5, and $20 \%$ for PSU concentration, 68 and $79 \%$ for humidity, 60 and $120 \mathrm{~L} / \mathrm{h}$ for flow rate, and $312.15,313.15$, and $321.15 \mathrm{~K}$ for temperature were specified for designing our experimental procedures. Furthermore, the reliability of the models was evaluated by comparing the results obtained from the experimental runs and the calculated data from the COMSOL analysis. Finally, the most appropriate model was selected for analyzing the structure and performance of the proposed membrane by determining the most optimized operating points of PSU concentration, solvent types, temperature, humidity, and flow rate. This optimization is considered to be highly beneficial for proposing a fabrication route to achieve a membrane with the maximum performance capabilities possible. In the following section, process modeling, membrane fabrication and characterization, and dehumidification test are discussed, respectively.

\section{Process modeling}

Figure 1 shows the membrane-formed module of parallel-plate channels along with the air and solution stream flow through the channels in a parallel-flow arrangement to facilitate duct sealing. Accordingly, a membrane and two neighboring flow channels were selected for the calculation domain to achieve the desired symmetry and

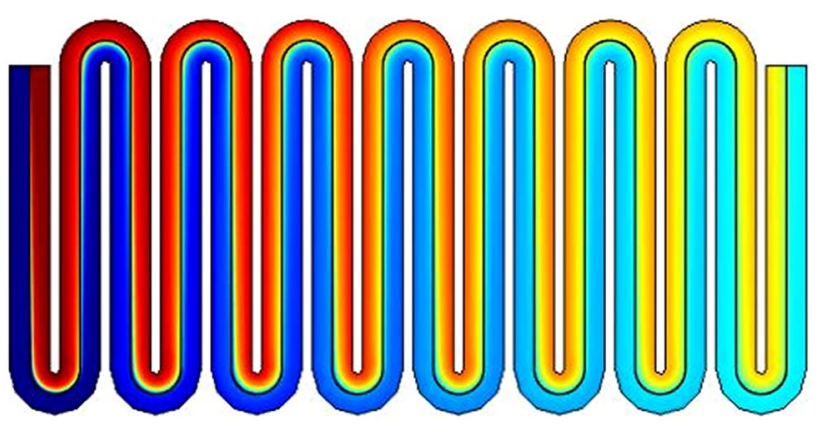

Fig. 1 Module of parallel-plate channels

calculation feasibility of the proposed model. Moreover, the COMSOL 5.3 software was used to perform two-dimensional modeling for flat membrane systems employing the laminar flow regimen of a single-phase fluid for the measurement of the velocity and pressure. The incompressible and compressible flows, as well as non-Newtonian fluids, are supported by physics interface at low Mach numbers $(<0.3)$. The laminar flow interface was solved by using the Navier equations and continuity equation to maintain the momentum and mass, respectively. The Navier equation in its most general form was employed as follows:

$\rho(U \cdot \nabla) U=\nabla \cdot\left[-\rho I+\mu\left(\nabla U+(\nabla U)^{T}\right)\right]+F \quad \rho \nabla \cdot(U)=0$.

Fluid properties-air equations:

$\rho(U \cdot \nabla) U=\nabla \cdot\left[-\rho I+\mu\left(\nabla U+(\nabla U)^{T}\right)\right]+F \quad \rho \nabla \cdot(U)=0$.

Wall 1 equation:

$U=0$.

Fluid properties-Li Cl equations:

$\rho(U \cdot \nabla) U=\nabla \cdot\left[-\rho I+\mu\left(\nabla U+(\nabla U)^{T}\right)\right]+F \quad \rho \nabla \cdot(U)=0$.

Inlet-air equation:

$U=-U_{0} \mathbf{n}$.

Inlet-LiCl equation:

$U=-U_{0} \mathbf{n}$.

Outlet equations:

$\left[-P I+\mu\left(\nabla U+(\nabla U)^{T}\right)\right] \boldsymbol{n}=-\hat{P}_{0} n \quad \hat{P}_{0} \leq P_{0}$.

The characterization of flow variables and fluid features of each point inside the medium is defined by using the 
mean and actual values of variables. The obtained properties of a given volume around the designated point in porous domains were also utilized for achieving a significant definition. It is worth mentioning that the control volume should be large enough to the extent that exceeds the volume of pores and elements of the solid matrix. However, it needs to be small compared to the volumes and the dimension of the macroscopic problems as defined in the model. A fraction of the control volume occupied by pores defined as porosity which could vary in a very small magnitude in regions that are purely solid to integrate with free flow domains. Volume averages corresponding to the pore unit volume is defined as the physical property of the fluid such as values of density and viscosity. The specified values that exist in the neighboring free flow were designated to be corresponding physical parameters, which are experimentally measurable. Overall, the flow velocity is defined as the volume average referring to a unit volume of the medium including pores and matrix. It is also referred to Darcy velocity that is defined as the cross-sectional volume per unit of medium flow rate.

Finally, based on the above definitions, the velocity continues throughout the boundaries from porous regions to free flow ones. The Darcy velocity and pressure are the dependent variables of the Brinkman equations. The combination of continuity equation with the momentum equation governs the flow of the porous media. Brinkman equation is derived from the combination of equations as follows:

$$
\begin{gathered}
\frac{1}{\epsilon_{P}} \rho(U \cdot \nabla) U \frac{1}{\epsilon_{P}}=\nabla \cdot\left[-P I+\mu \frac{1}{\epsilon_{P}}\left(\nabla U+(\nabla U)^{T}\right)\right] \\
-\left(\mu K^{-1}+\beta_{F}|U|+\frac{Q_{\mathrm{br}}}{\epsilon_{P}^{2}}\right) U+F \quad \rho \nabla \cdot(U)=Q_{\mathrm{br}} .
\end{gathered}
$$

Furthermore, to measure the concentration of the diluted solute, and the reaction rate of gas, liquid, or solid dissolved species, the transportation rate of the diluted species was measured and utilized. The Fick law of convection was further applied to obtain the transport driving force and diffuse migration by coupling with those of fluid flow and electric field, respectively. The utilized equations of Fick law are as follows:

$$
\begin{aligned}
& \nabla \cdot\left(-D_{i} \nabla_{\mathrm{ci}}\right)+U \cdot \nabla_{\mathrm{ci}}=R_{i}, \\
& -N \cdot D_{i} \nabla_{\mathrm{ci}}=0_{\mathrm{Ni}}=-D_{\mathrm{i}} \nabla_{\mathrm{ci}}+U_{\mathrm{ci}} .
\end{aligned}
$$

Inflow-air equation:

$C_{i}=C_{0 j}$.

Inflow-Li Cl equation:
$C_{i}=C_{0 j}$

Apart from the convection and diffusion equations, the node has the functionality to measure the evolution of species through adsorption and dispersion mechanisms.

Membrane equation:

$\nabla \cdot R_{i}+U \cdot \nabla_{\mathrm{ci}}=R_{i}+S_{i} \quad N_{i}=R_{i}+U_{\mathrm{ci}}=-D_{\mathrm{ej}} \nabla_{\mathrm{ci}}+U_{\mathrm{ci}}$.

Air equation:

$\nabla \cdot\left(D_{i} \nabla_{\mathrm{ci}}\right)+U \cdot \nabla_{\mathrm{ci}}=R_{i} \quad N_{i}=-D_{i} \nabla_{\mathrm{ci}}+U_{\mathrm{ci}} \cdot$

Li Cl equation:

$\nabla \cdot\left(-D_{i} \nabla_{\mathrm{ci}}\right)+U \cdot \nabla_{\mathrm{ci}}=R_{i} \quad N_{i}=-D_{i} \nabla_{\mathrm{ci}}+U_{\mathrm{ci}}$.

\section{Membrane fabrication and characterization}

In this project, the wet-phase inversion procedure was applied to fabricate the designated membranes. Firstly, casting solutions with different solvents such as NMP and DMF were prepared. The prepared solutions were mixed using a magnetic stirrer for $24 \mathrm{~h}$ at room temperature. Secondly, a casting machine was employed to disperse the obtained solution on a glass support. Finally, the obtained polymer films floated on a coagulation bath containing deionized water until their inversion process was complete. It is worth mentioning that by knowing the pore volume of the membranes and their membrane volume, it is possible to measure its porosity. Therefore, Density of dry and wet membranes was measured and the results were recorded which demonstrate a weight difference that could be due to presence of eater in its cavities that is the result of the density of water in the membrane.

\section{Dehumidification test}

Figure 2 shows the dehumidification setup, which was used for the measurement of outlet air $(\mathrm{RH})$ and the evaluation

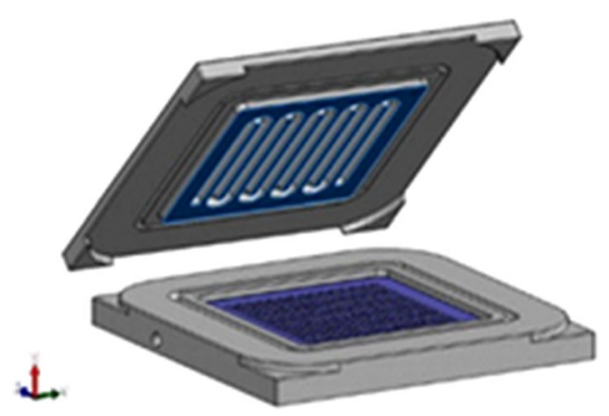

Fig. 2 Membrane module design 
of the dehumidification membrane module Table 1 shows the Membrane properties, contactor specifications and transport properties. As stated earlier, the membrane module was assembled using a membrane with two different flow fields for humid air and liquid $\mathrm{Li} \mathrm{Cl}$. The most important control factors such as flow rate, pressure, and temperature of gas and $\mathrm{LiCl}$, were controlled. A humidity indicator (digital thermometer and hygrometer-DT-3) was also employed to measure the gas RH. Since the membranes have a porous structure, the pressure was kept constant on both sides of the membrane, while the transfer of water vapor responded to the difference in chemical potentials. Additionally, a temperature indicator controller was embedded inside, and a mechanical mixer was utilized to keep the temperature constant at the specified temperature points of $312.15,313.15$, and $321.15 \mathrm{~K}$. The gas flow tube was a serpentine channel with a specific length, $6 \mathrm{~mm}$ width, and $5 \mathrm{~mm}$ surface contact with the membrane. The effective surface of the membrane in the module was $5 \times 1800 \mathrm{~mm}^{2}$. The $\mathrm{LiCl}$ flow field was a simple container with a reticular plate to hold the membrane. In each run, the samples of the membranes with the size of $15 \times 15 \mathrm{~cm}$ were examined in different designated

Table 1 Membrane properties, contactor specifications, and transport properties

\begin{tabular}{llllll}
\hline Symbols & Unit & Values & Symbols & Unit & Values \\
\hline$L$ & $\mathrm{~mm}$ & 946 & $\mathrm{ma}$ & $\mathrm{kg} / \mathrm{h}$ & 60 \\
$d$ & $\mathrm{~mm}$ & 6 & $\mathrm{~ms}$ & $\mathrm{~kg} / \mathrm{h}$ & 45 \\
$w$ & $\mathrm{~mm}$ & 5 & $\omega_{\mathrm{a}, \text { in }}$ & $\mathrm{g} / \mathrm{kg}$ & 0.22 \\
$D_{\text {vmem }}$ & $\mathrm{m}^{2} / \mathrm{s}$ & $7.89 * 10^{-6}$ & $\omega_{\mathrm{s}, \text { in }}$ & $\mathrm{g} / \mathrm{kg}$ & 0.0055 \\
$D_{\text {va }}$ & $\mathrm{m}^{2} / \mathrm{s}$ & $2.82 * 10^{-5}$ & $X_{\mathrm{s} \text { in }}$ & $\mathrm{kg} / \mathrm{kg}$ & \\
$D_{\mathrm{vs}}$ & $\mathrm{m}^{2} / \mathrm{s}$ & $3.00 * 10^{-9}$ & $X_{\mathrm{s} . \mathrm{e}}$ & $\mathrm{kg} / \mathrm{kg}$ & \\
$\delta_{\mathrm{mem}}$ & $\mathrm{mm}$ & 0.3 & $T_{\text {a, in }}$ & ${ }^{\circ} \mathrm{C}$ & 30 \\
$\rho_{\mathrm{a}}$ & $\mathrm{Kg} / \mathrm{m}^{3}$ & 1.1615 & $T_{\mathrm{s}, \text { in }}$ & ${ }^{\circ} \mathrm{C}$ & 25 \\
$\rho_{\mathrm{s}}$ & $\mathrm{Kg} / \mathrm{m}^{3}$ & 1215 & & & \\
$\rho_{\mathrm{w}}$ & $\mathrm{Kg} / \mathrm{m}^{3}$ & 1003 & & & \\
\hline
\end{tabular}

conditions for mechanical tests. The effects of the operating conditions and the membrane synthesis parameters on dehumidification were evaluated using the apparatus described earlier. The composition of the casting solution was an important factor affecting the position, shape, and orientation of the formed cavities, which had certain impacts on the dehumidification performance. Accordingly, six membranes were prepared, and their attributed experimental data are shown in Table 2.

\section{Results and discussion}

\section{Model validation}

\section{Experimental validations}

As indicated in Fig. 3a, the dehumidification setup was prepared and operated at different operating conditions to evaluate their impact on the performance and characteristics of the membranes (Table 2). Therefore, a module was designed using the COMSOL software, which facilitated validating the experimental results from the mathematical perspective. All the experimental runs were performed isothermally for at least three times to confirm the significance of the results

Table 2 The weight percentage of the polymer and the composition of solvent in different membranes

\begin{tabular}{lccl}
\hline Membrane type & \multicolumn{2}{l}{ Solvent compound (\%) } & $\begin{array}{l}\text { Polymer weight (\%) } \\
\text { Polysulfone }\end{array}$ \\
\cline { 2 - 3 } & DMF & NMP & \\
\hline PSU-NMP-1 & 0 & 100 & 20 \\
PSU-NMP-2 & 0 & 100 & 17.5 \\
PSU-NMP-3 & 0 & 100 & 15 \\
PSU-DMF-1 & 100 & 0 & 20 \\
PSU-DMF-2 & 100 & 0 & 17.5 \\
PSU-DMF-3 & 100 & 0 & 15 \\
\hline
\end{tabular}

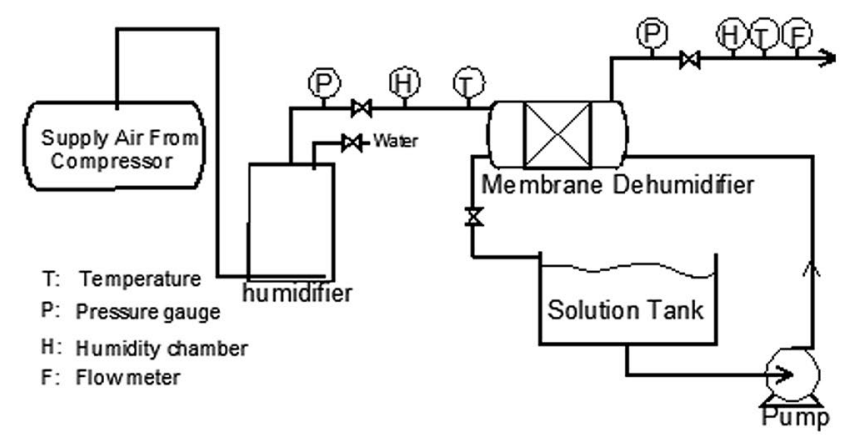

(a)

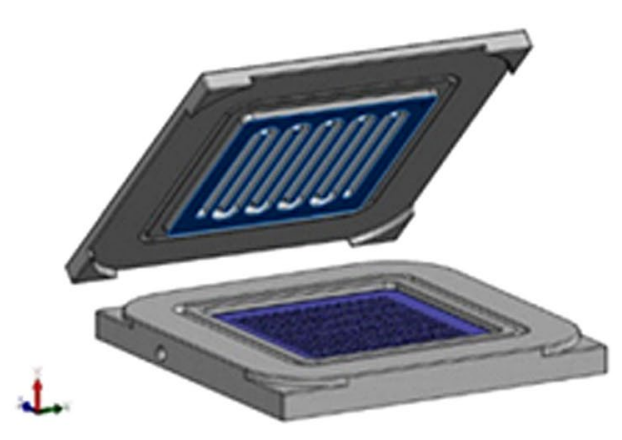

(b)

Fig. 3 a Dehumidification setup design and $\mathbf{b}$ membrane module design 
Table 3 Experimental and numerical data of the dehumidification setup

\begin{tabular}{|c|c|c|c|c|c|c|c|c|}
\hline \multirow[t]{2}{*}{ Number } & \multirow{2}{*}{ Membrane type } & \multirow[t]{2}{*}{ Poruse } & \multicolumn{3}{|c|}{ Operating conditions } & \multicolumn{3}{|l|}{ Parameters } \\
\hline & & & Flow Rate (L/h) & $\begin{array}{l}\text { Rela- } \\
\text { tive humidity } \\
\text { in }(\%)\end{array}$ & Tai $\left({ }^{\circ} \mathrm{K}\right)$ & $\begin{array}{l}\text { Relative humidity } \\
\text { out, } \exp (\%)\end{array}$ & $\begin{array}{l}\text { Relative humidity } \\
\text { out, call (\%) }\end{array}$ & Error $(\%)$ \\
\hline 1 & PUS-NMP-1 & 0.40 & 60 & 79 & 312.15 & 47.5 & 45.96 & 3.3 \\
\hline 2 & & & 60 & 79 & 321.15 & 43.1 & 40.85 & 5.2 \\
\hline 3 & & & 60 & 68 & 312.15 & 41.4 & 40.02 & 3.3 \\
\hline 4 & & & 120 & 79 & 313.15 & 55.7 & 56.29 & 1.1 \\
\hline 5 & PUS-NMP-2 & 0.48 & 60 & 79 & 312.15 & 46.1 & 45.95 & 0.3 \\
\hline 6 & & & 60 & 79 & 321.15 & 43.6 & 40.84 & 6.3 \\
\hline 7 & & & 60 & 68 & 312.15 & 38.9 & 40.02 & 2.9 \\
\hline 8 & & & 120 & 79 & 313.15 & 55.1 & 56.29 & 2.2 \\
\hline 9 & PUS-NMP-3 & 0.51 & 60 & 79 & 312.15 & 44.7 & 45.95 & 2.8 \\
\hline 10 & & & 60 & 79 & 321.15 & 43 & 40.84 & 5.0 \\
\hline 11 & & & 60 & 68 & 312.15 & 39.1 & 40.02 & 2.3 \\
\hline 12 & & & 120 & 79 & 313.15 & 54.9 & 56.29 & 2.5 \\
\hline 13 & PUS-DMF-1 & 0.41 & 60 & 79 & 312.15 & 45.1 & 45.93 & 1.9 \\
\hline 14 & & & 60 & 79 & 321.15 & 41.3 & 40.83 & 1.1 \\
\hline 15 & & & 60 & 68 & 312.15 & 39.2 & 40.00 & 2.0 \\
\hline 16 & & & 120 & 79 & 313.15 & 55.7 & 56.27 & 1.0 \\
\hline 17 & PUS-DMF-2 & 0.50 & 60 & 79 & 312.15 & 44.7 & 45.92 & 2.7 \\
\hline 18 & & & 60 & 79 & 321.15 & 42.1 & 40.82 & 3.0 \\
\hline 19 & & & 60 & 68 & 312.15 & 40.8 & 40.00 & 2.0 \\
\hline 20 & & & 120 & 79 & 313.15 & 55.4 & 56.25 & 1.5 \\
\hline 21 & PUS-DMF-3 & 0.53 & 60 & 79 & 312.15 & 44.1 & 45.92 & 4.1 \\
\hline 22 & & & 60 & 79 & 321.15 & 42.3 & 40.81 & 3.5 \\
\hline 23 & & & 60 & 68 & 312.15 & 40.2 & 39.99 & 0.5 \\
\hline 24 & & & 120 & 79 & 313.15 & 53.9 & 56.25 & 4.4 \\
\hline
\end{tabular}

as listed in the Table 3. Hence, we obtained the calculated outlet humidity, and mass fraction of the air, as well as solution flows from the humidifier [25]. Overall, there was less than $6.3 \%$ discrepancy between the mathematical results and the experimental methods. From this evaluation, we could confirm the reliability of the module in predicting the performance of the membranes [26]. Furthermore, the proposed model by the COMSOL software was able to successfully predict and solve the heat and mass transfer problems in a flat membrane-based liquid desiccant air dehumidification model. The proposed module can be expressed as follows:

$e_{d}=\left(\omega_{\text {pin }}-\omega_{\text {pout }}\right) * 100 /\left(\omega_{\text {pin }}-\omega_{\text {pout,ideal }}\right)$,

where $\omega_{\text {pout,ideal }}$ is the absolute humidity which would be ideal for the initial airflow of the converter. By assuming that the air is completely dehumidified, most likely $\omega_{\text {pout,ideal }}$ would be close to zero.

\section{Simulation results}

The relative humidity of the output stream that was obtained from the mathematical simulation is listed in Table 3. Additionally, Fig. 4a shows the channel layout in the simulation in which its sequence type was selected as the main physical mesh control, while its element size was considered to be relatively coarse [27]. Figure $4 b$ shows the variations of velocity along the channel. It is clearly revealed that the velocity of the channel in the middle was maximal and the velocity along the walls was zero [28]. Figure 5a also depicts the pressure variations along the channel, which due to the presence of the porous membrane remained constant across the channel with no noticeable variations. As shown in Fig. 5b, the effect of membrane composition induced variations in both air and soluble concentration along the length of the channel [29]. Accordingly, air concentration decreased by increasing the airflow through the membrane surface, while the solution concentration increased, indicating the transfer of moisture from the air to liquid [30]. 

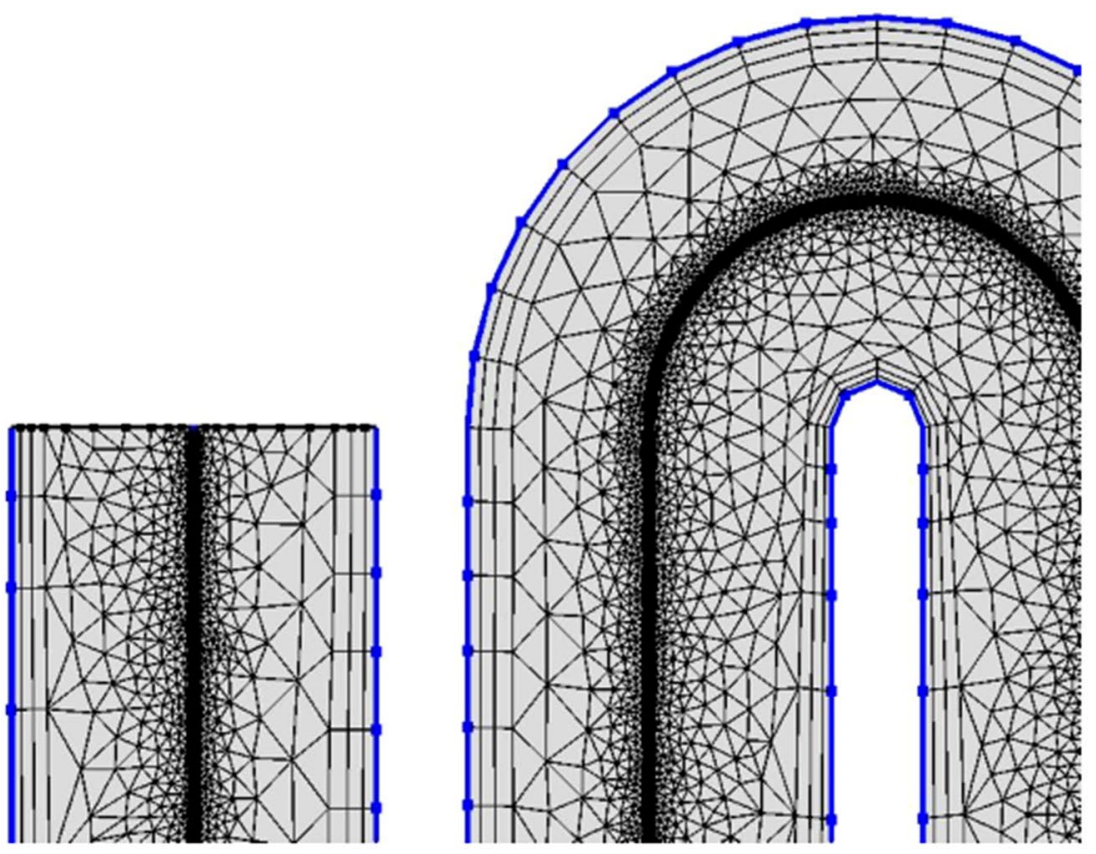

(a)

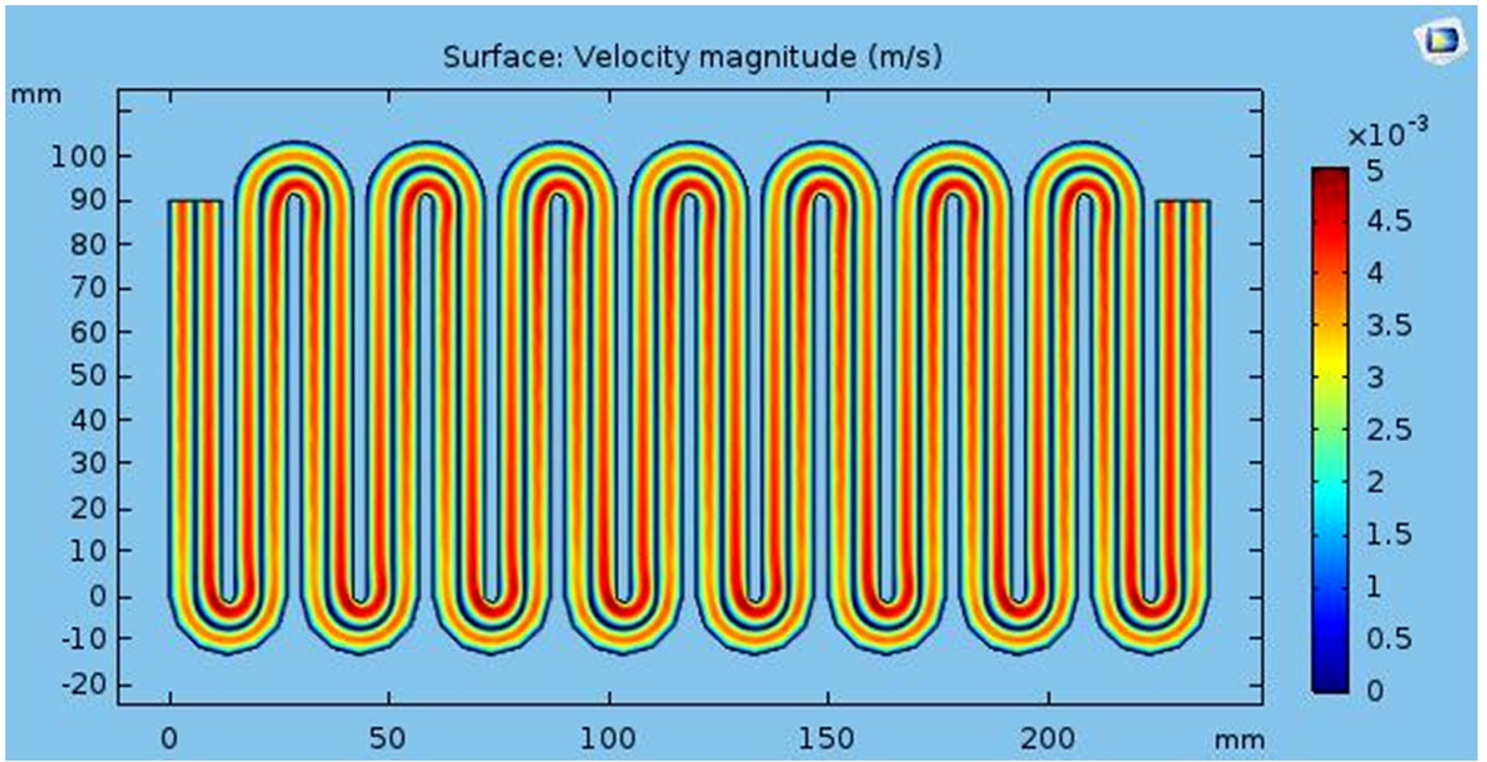

(b)

Fig. 4 Mesh structure $\mathbf{a}$ and velocity changes $\mathbf{b}$ along the module membrane

\section{Effects of solvent type and porosity}

Figure 6 a shows that the impact of solvent type and porosity of the membranes varied due to the presence of DMF or NMP with different weight percentages on the porosity of the membranes. According to the obtained results, the membranes with DMF solvent had high dehumidification, and the relative humidity of the outlet air substantially lower compared to the membranes containing the NMP. This clearly indicates that the dehumidification efficiency of the former samples is higher than that of the previous one. Figure $6 \mathrm{~b}$ also shows the positive impact of solvent porosity on the efficiency of the dehumidification procedure, as the amount of relative humidity of the outlet air was decreased significantly in the samples containing the DMF [31]. We further attempted to assess the observed 


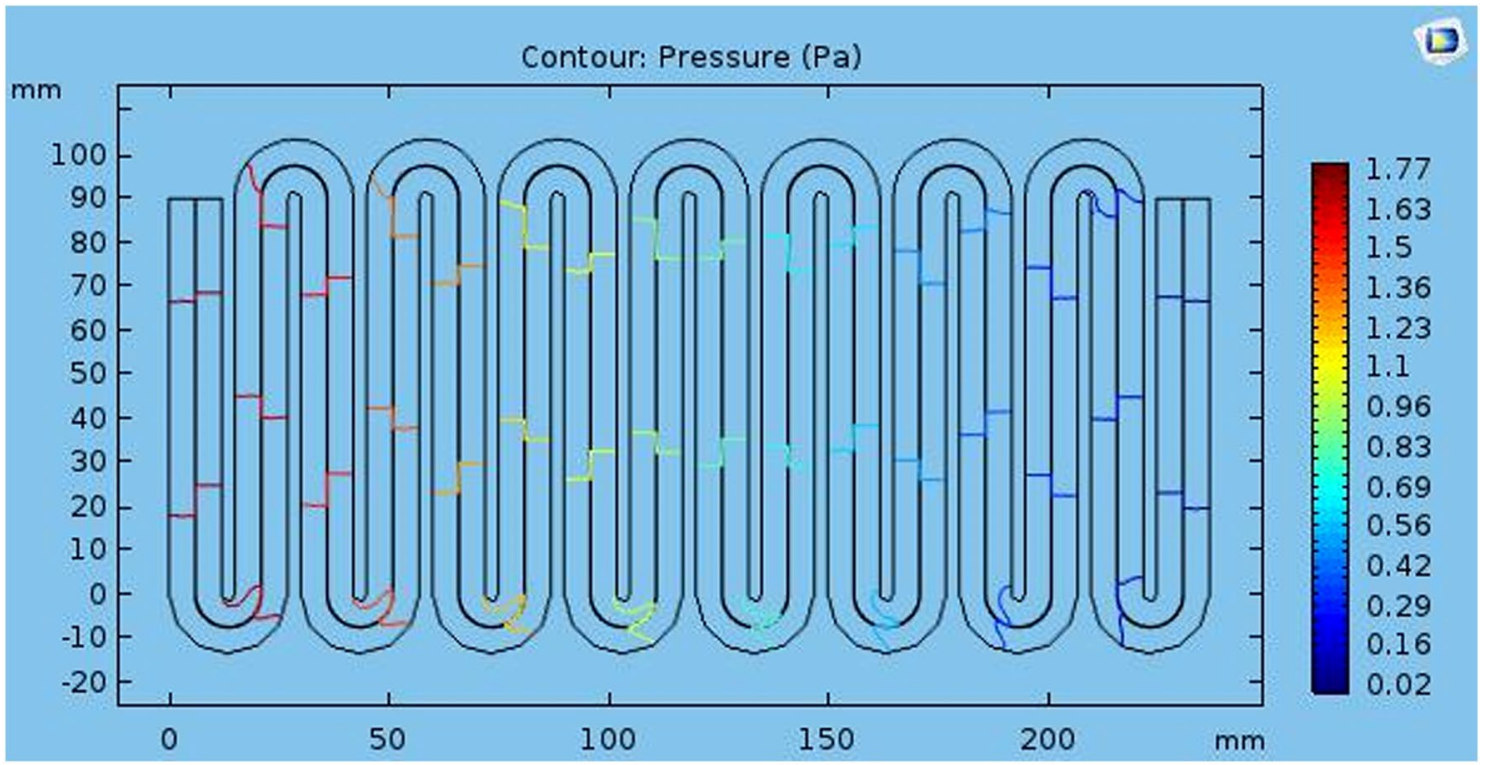

(a)

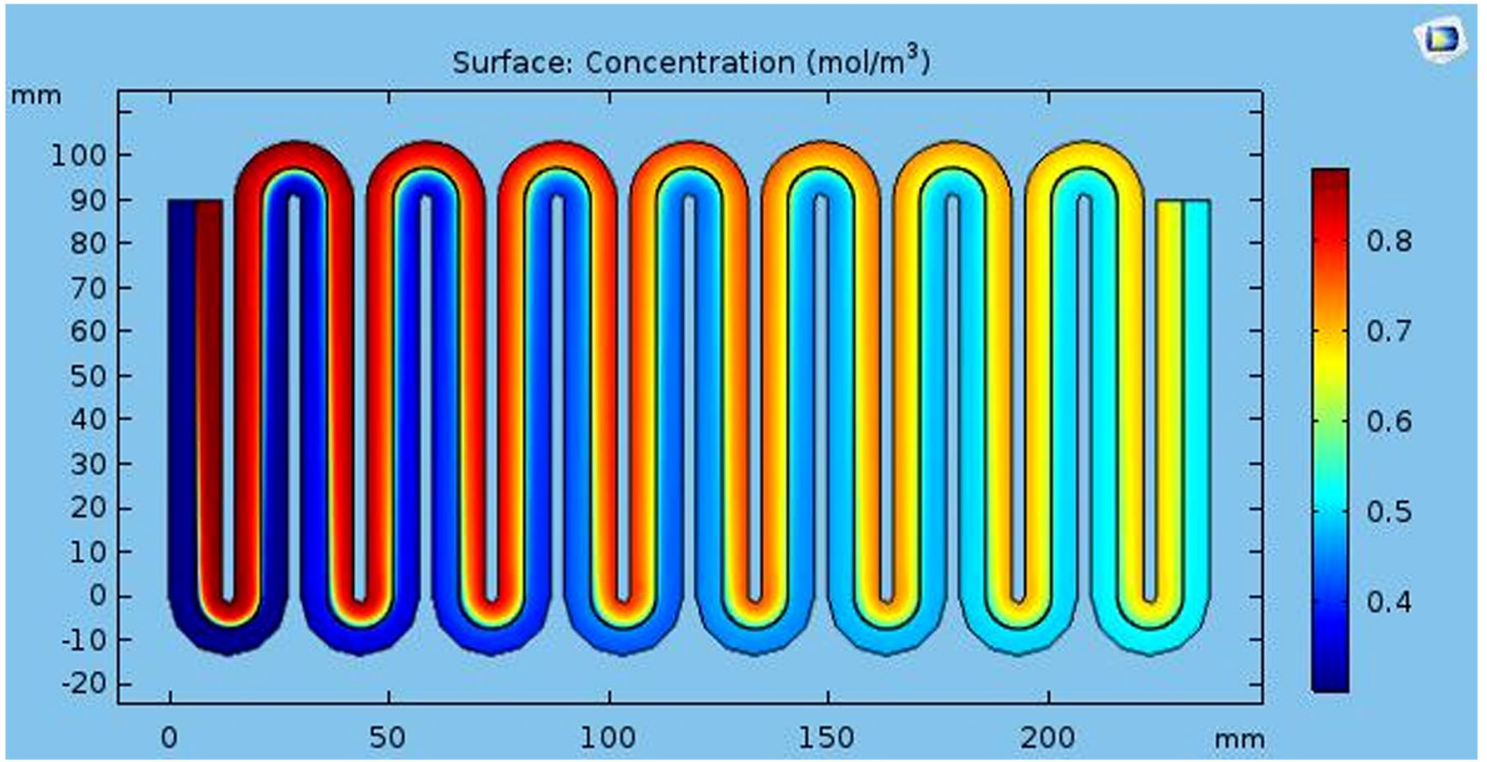

(b)

Fig. 5 Pressure $\mathbf{a}$ and concentration $\mathbf{b}$ changes along the membrane

differences in the values of the moisture flux of the samples with different solvents using the scanning electron microscope (SEM) analysis. As shown in Figs. 7 and 8, the median pore diameter in the DMF containing membranes was smaller, and the number of pores was higher. Therefore, it can be concluded that the DMF had more interaction with moist air and thus resulted in a more enhanced air dehumidification yield [32]. According to Fig. 7, the bottom layer of membrane containing the DMF solvent was larger in size, which allowed less liquid desiccant to diffuse deeper into the membrane. It should be mentioned that unlike air, the membrane was not nearly capable of letting the liquid desiccant to diffuse into it, thus allowing an easier transmittance of the DMF solvent [33].

\section{Effect of air flow rate}

The impact of the inlet flow rate on the humidity of air and consequently the efficiency of the membranes in the dehumidification process are summarized in Table 3. It is noted 
Flow rate $=60(\mathrm{~L} / \mathrm{h}), \mathrm{Rh}=79(\%), \mathrm{Tai}=312.15(\mathrm{~K})$

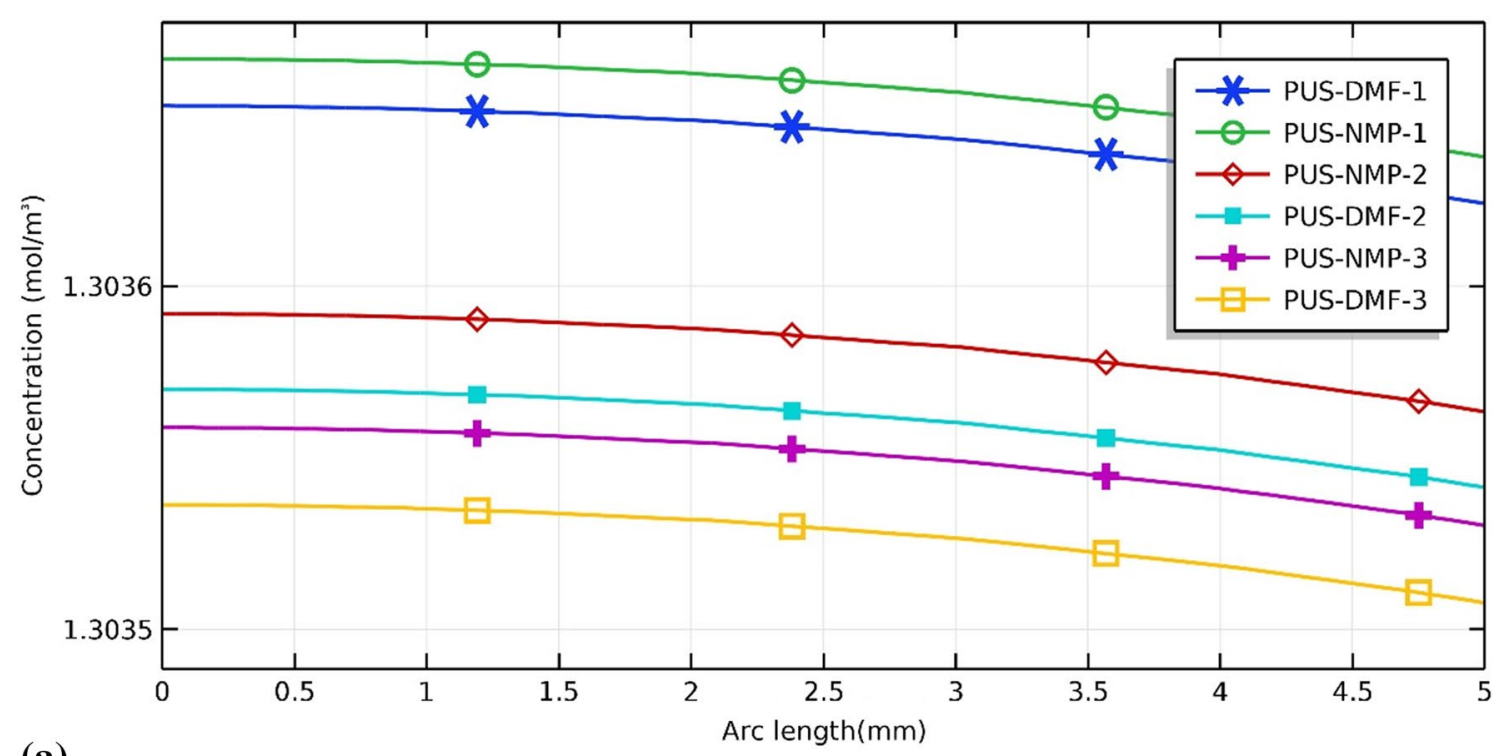

(a)

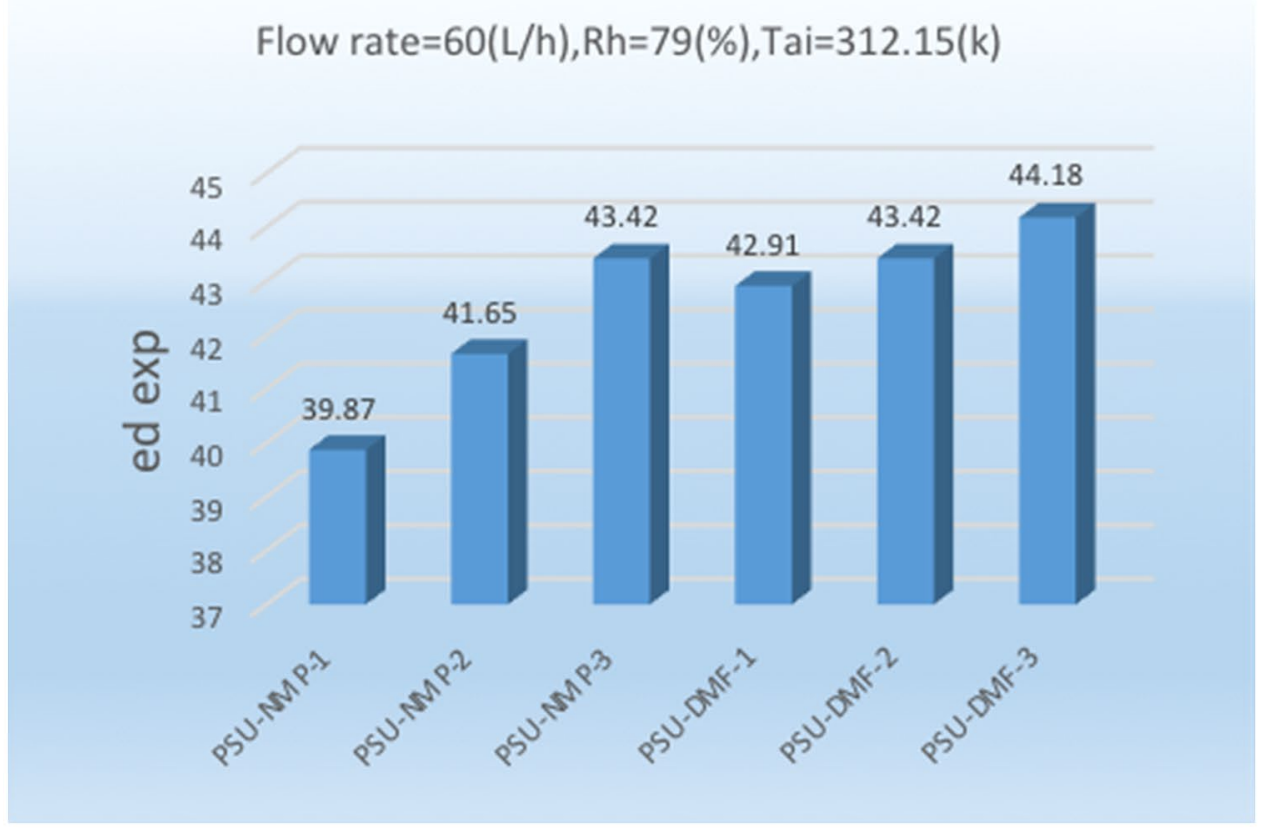

(b)

Fig. 6 Concentration of air outlet across channel $\mathbf{a}$ and dehumidification efficiencies $\mathbf{b}$ for different solvents and different porosities

in the literature that with increasing AIFR from 60 to 120 $\mathrm{L} / \mathrm{h}$ and the stability of the discharge rate for all the synthesized membranes, the humidity of the air will be less affected and the absorption of moisture from the air besides the dehumidification rate will decrease as well [34]. When the AIFR increases, due to the constant cross section, air velocity increases as well; thus, the air stagnation time period decreases and air mass remains constant over an area for an extended period. The simulation results are presented in the following sections for different flows (Fig. 9). According to the findings, by increasing the airflow percentage, the air concentration decreases, and the efficiency of dehumidification also drops [35]. 

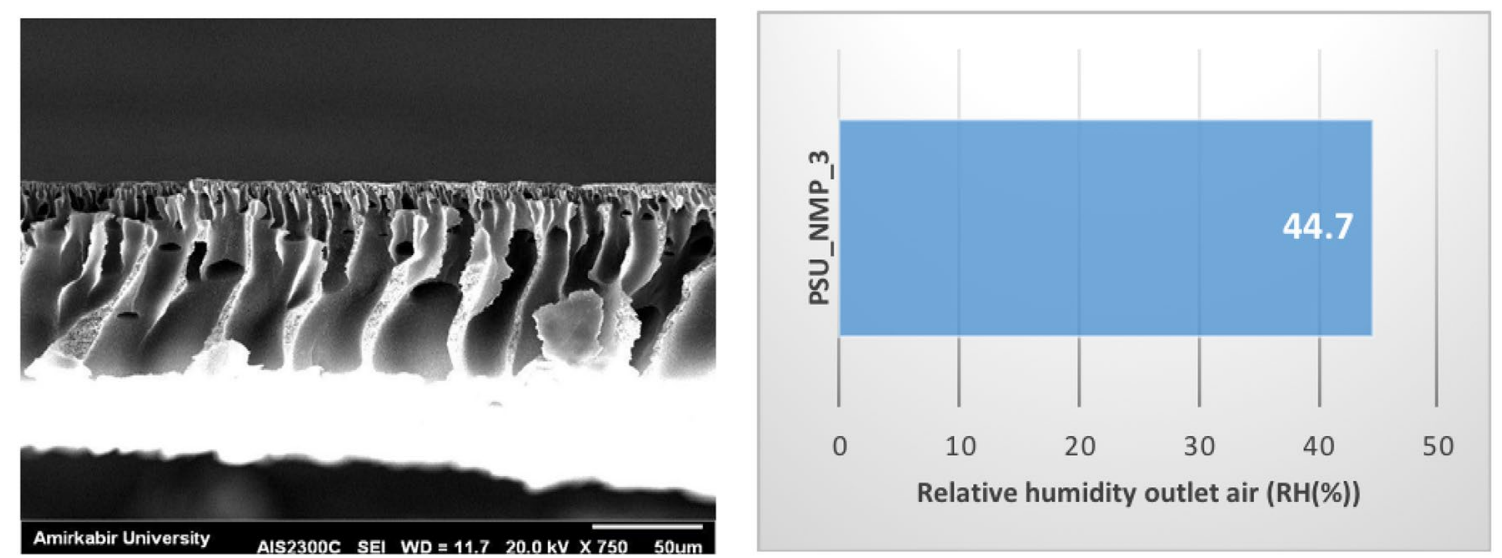

(a)
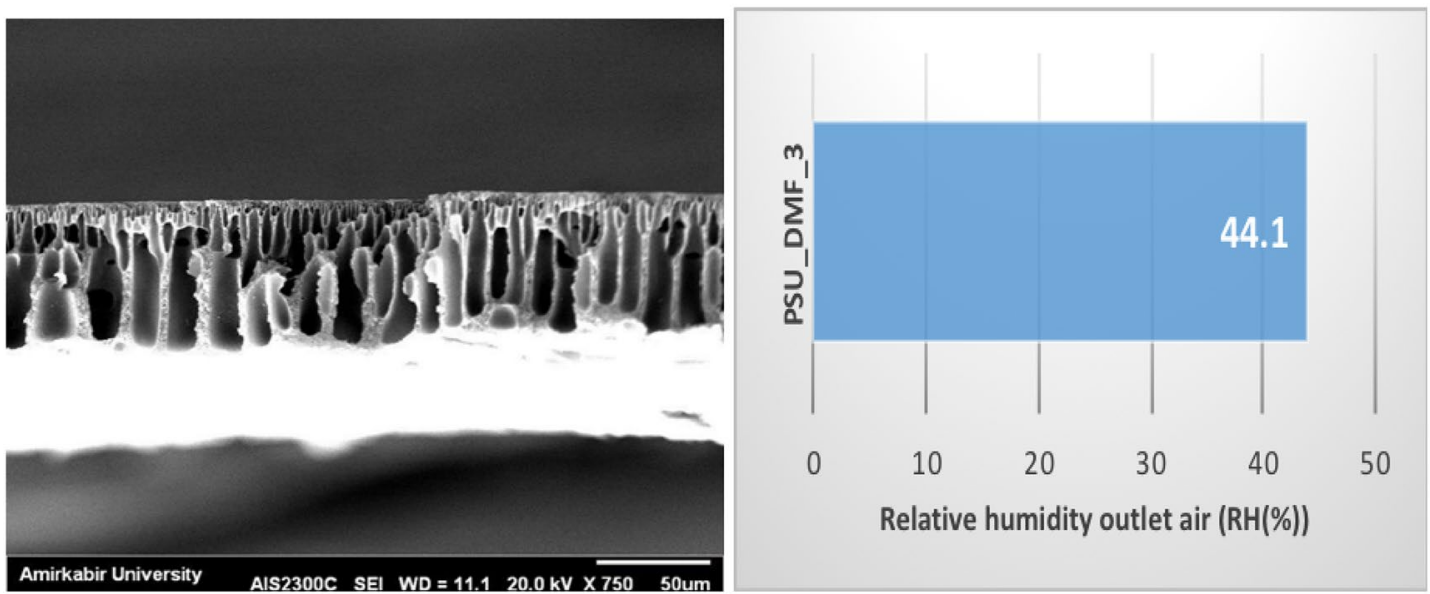

(b)

Fig. 7 SEM image from the membrane cross section PSU-NMP-3 (a) and SEM image from the membrane cross section PSU-DMF-3 (b)

Fig. 8 SEM images from the surface of PSU-NMP-3 (a) and SEM image from the surface of PSU-DMF-3 (b)

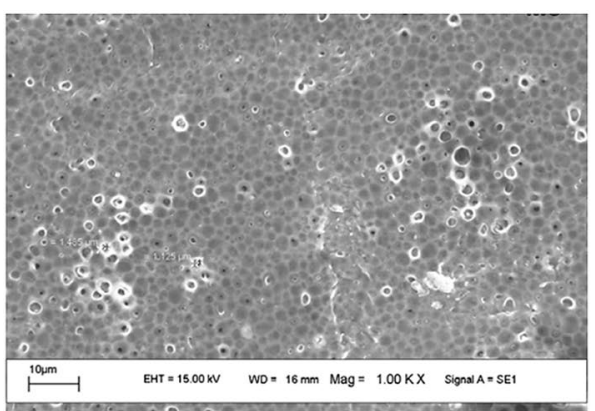

(a)

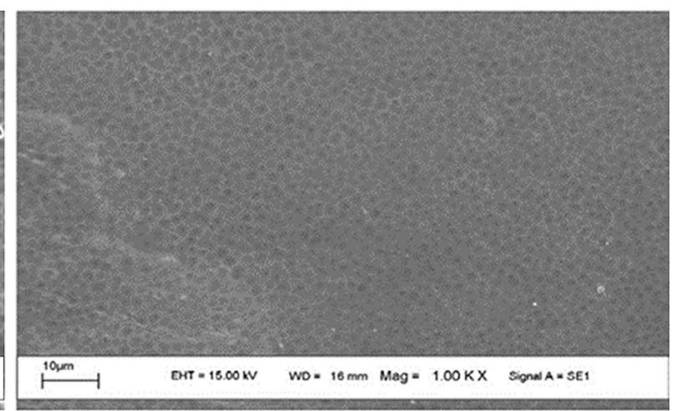

(b)

\section{Effects of humidity and temperature}

The impact of the increasing moisture while the temperate and input flow rate stay constant is shown in Fig. 10 and 11. Additionally, increasing the relative humidity results in the increase of the air concentration [36]. Equation (14) is defined as follows:
$N_{\mathrm{W}}=K_{\mathrm{m}} *\left(X_{\mathrm{W}} * \gamma_{\mathrm{W}} * P-Y_{\mathrm{W}} * P^{\mathrm{sat}}\right)$,

$\varphi=X_{\mathrm{W}} * P / P^{\mathrm{sat}}$.

The membrane was expected to increase the moisture flux as verified by the implication of the modules. It should be 
PSU-NMP-1, Rh=79(\%).Tai $=312.15(\mathrm{k})$

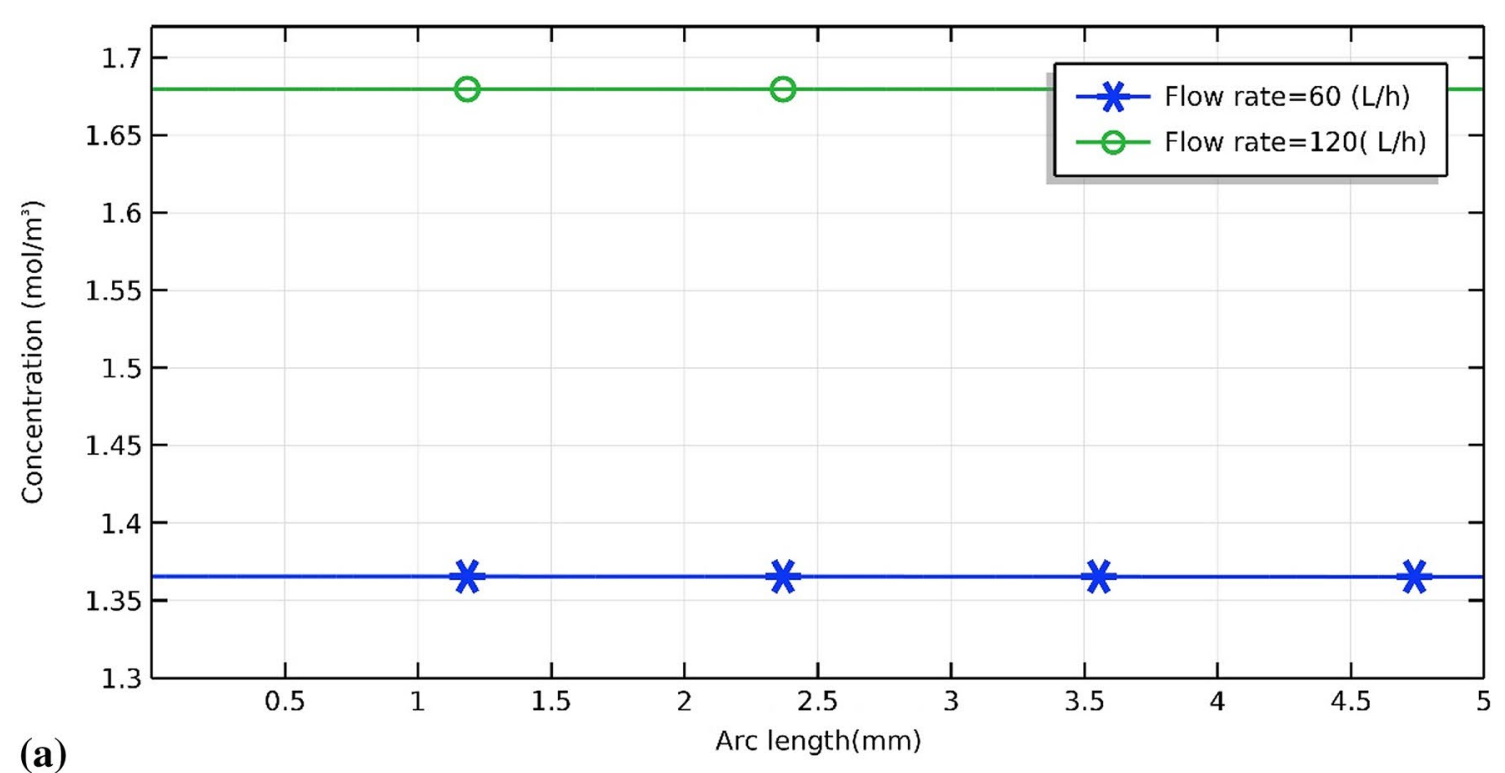

(a)

PSU-NMP-1,Rh=79(\%),Tai=312.15(K)

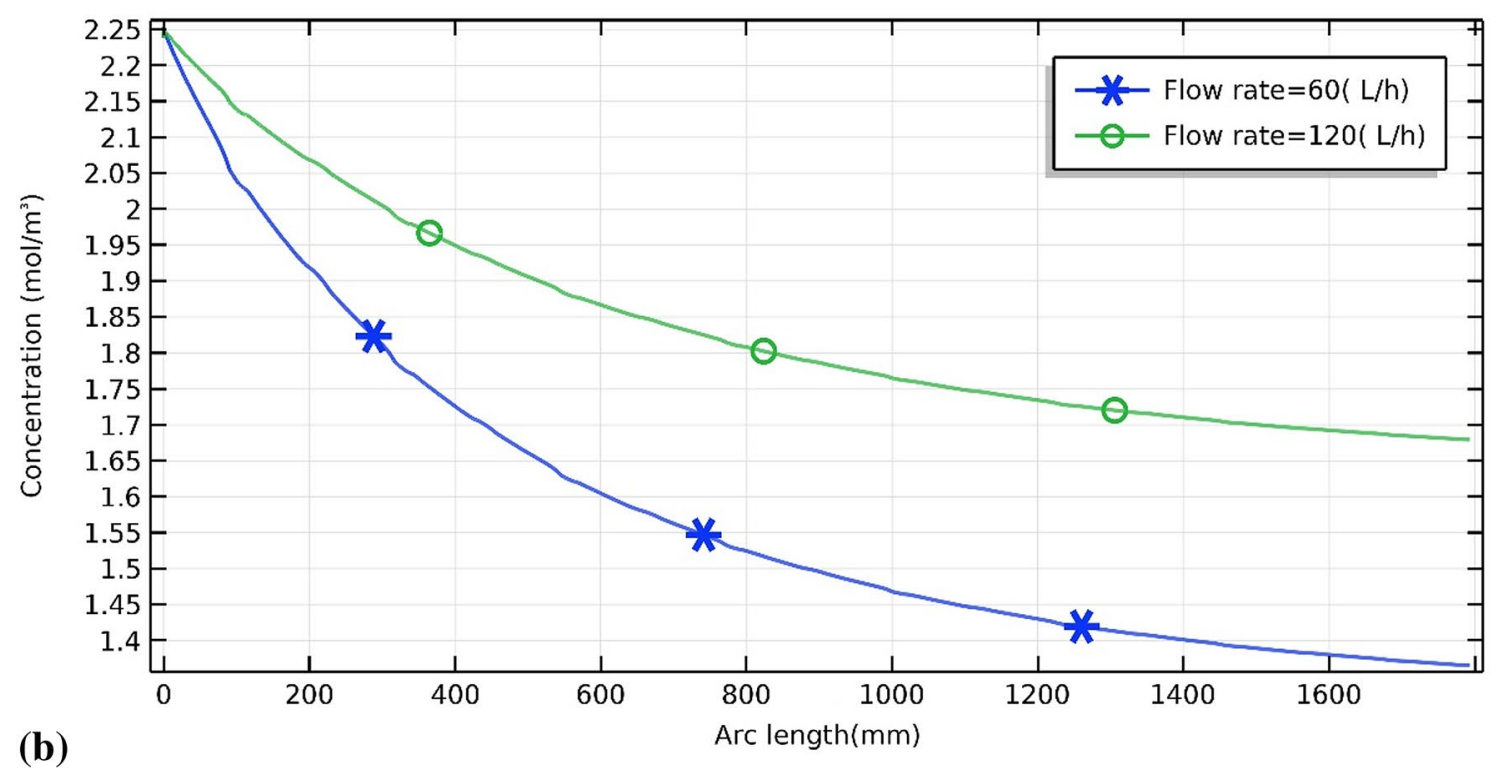

Fig. 9 Concentration of air outlet across the channel $\mathbf{a}$ and concentration variations along the membrane $\mathbf{b}$ for different air flow rates

noted that in Eqs. 14 and 15, $N_{\mathrm{W}}$ is the moisture flux, $K_{\mathrm{m}}$ is the overall mass transfer coefficient in the membrane. $X_{\mathrm{W}}$ stands for the mole fraction of moisture in the air, $\gamma_{\mathrm{W}}$ is the activity coefficient of moisture, $Y_{\mathrm{W}}$ is the mole fraction of moisture in liquid, $\mathrm{P}$ and $P^{\mathrm{sat}}$ are the total pressure and water saturated pressure, respectively, and $\varphi$ is the relative humidity.
Also, if the relative humidity is kept constant and the temperature is raised, according to the diagram of the pyrometer, we noticed that the percentage of humidity in the air also increases. The same phenomenon is also applied to Eq. (14), as the transferred flux also increases following the same path [37].

According to Table 3, the overall results indicate that in all the membranes evaluated in this study, increasing the 


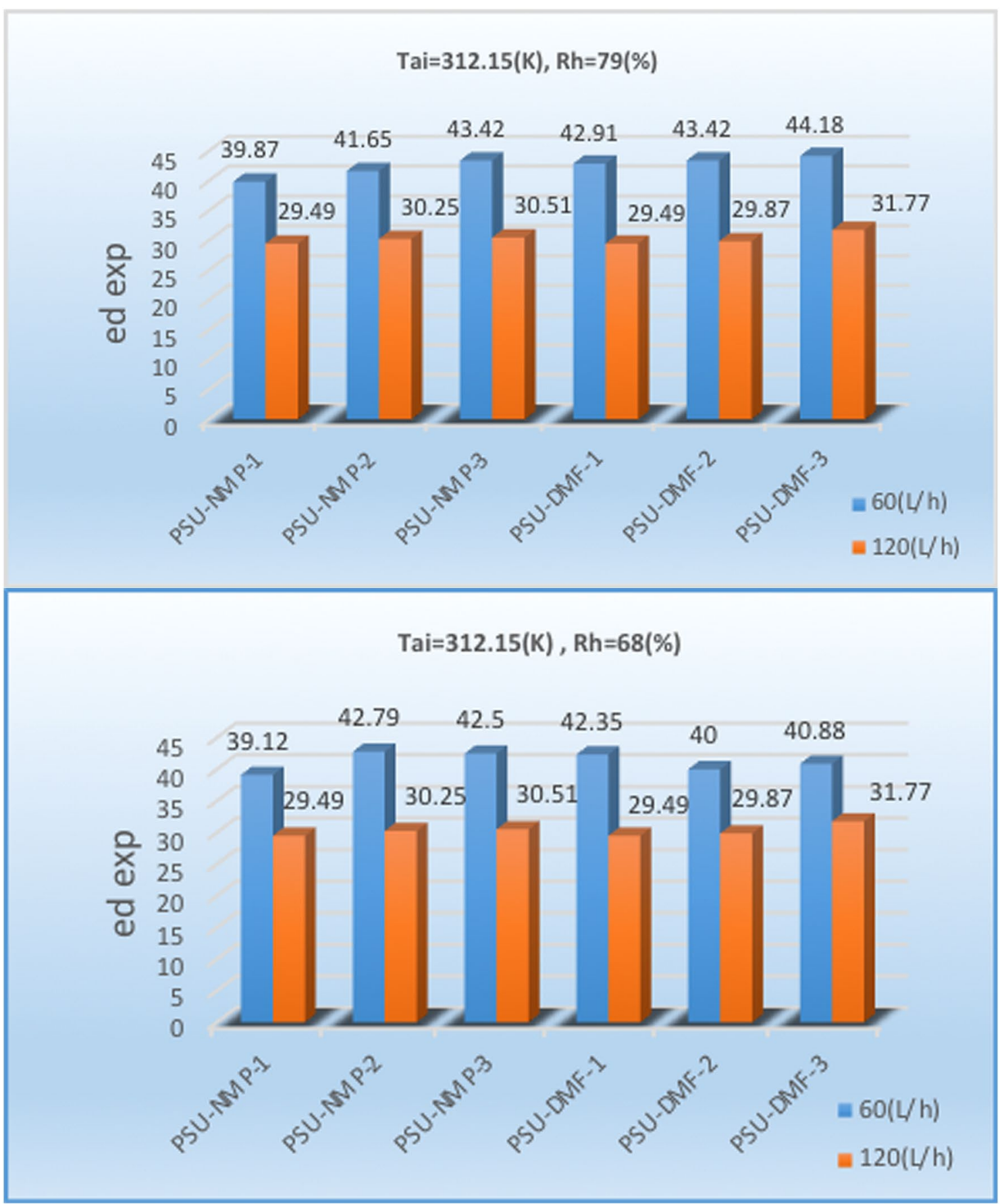

Fig. 10 Dehumidification efficiencies for different humid rates

temperature and humidity from 39 to $48{ }^{\circ} \mathrm{C}$ and 68 to $79 \%$ caused the efficiency of dehumidification to rise from 42 to $48 \%$ in all the membranes [38]. Thus, it was concluded that in any area with a warm and humid climatic condition, the most appropriate efficiency could be achieved. Additionally, by increasing the amount of intake air, the relative humidity of the outlet air was also diminished in the synthesized membranes. Under other conditions, increasing the air velocity results in the reduction of the amount of air outlet [39]. In conclusion, the results of this study indicate that the synthesized membranes most likely demonstrate remarkable performance in hot and humid climates as compared with other fabricated membranes (Figs. 12, 13). Therefore, they can be considered as reliable membranes for the dehumidification in areas with extreme climactic conditions in terms of humidity and temperature [40]. 
PSU-NMP-1,Flow rate $=60(\mathrm{~L} / \mathrm{h}), \mathrm{Tai}=313.15(\mathrm{~K})$

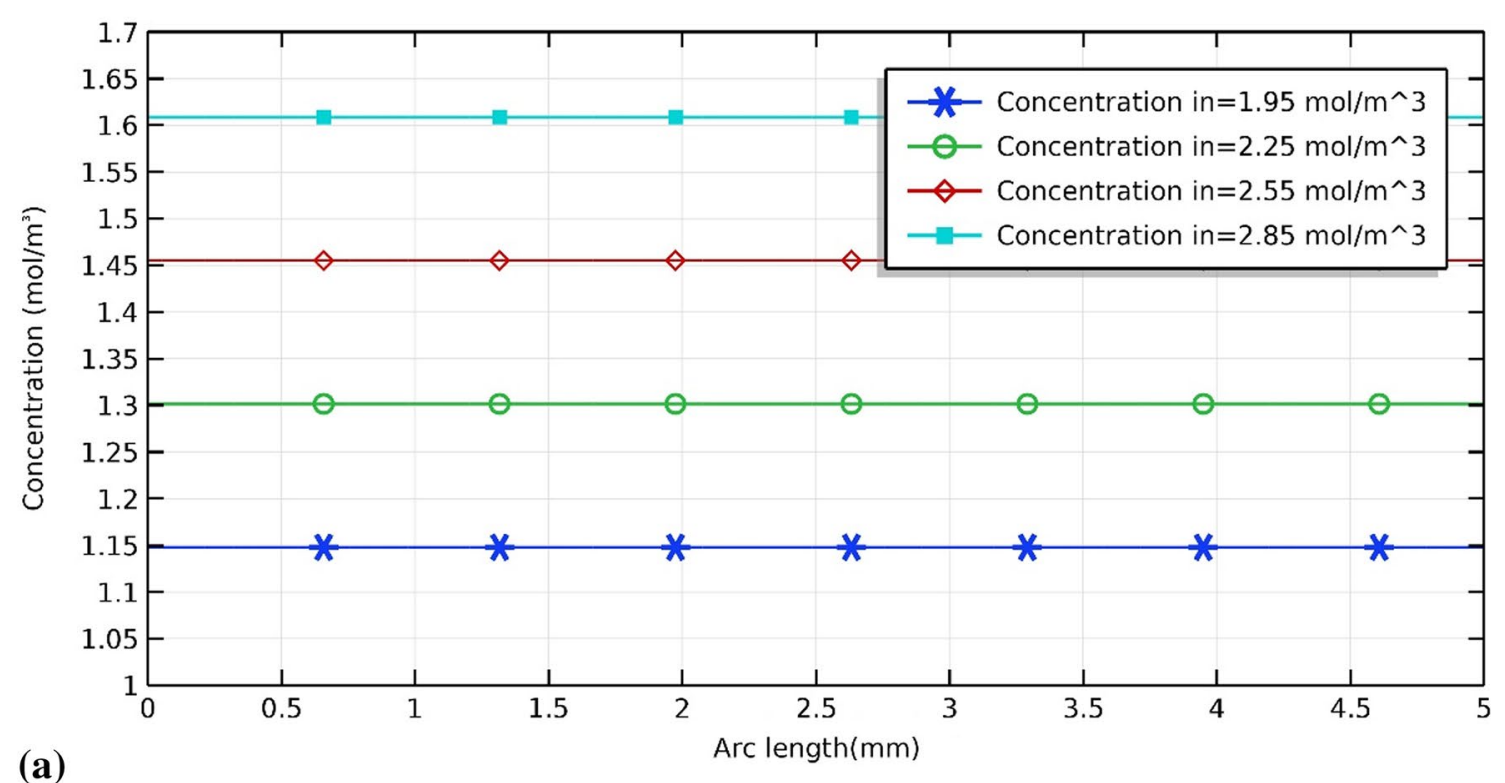

(a)

PSU-NMP-1,Flow rate $=60(\mathrm{~L} / \mathrm{h})$, Tai $=313.15(\mathrm{~K})$

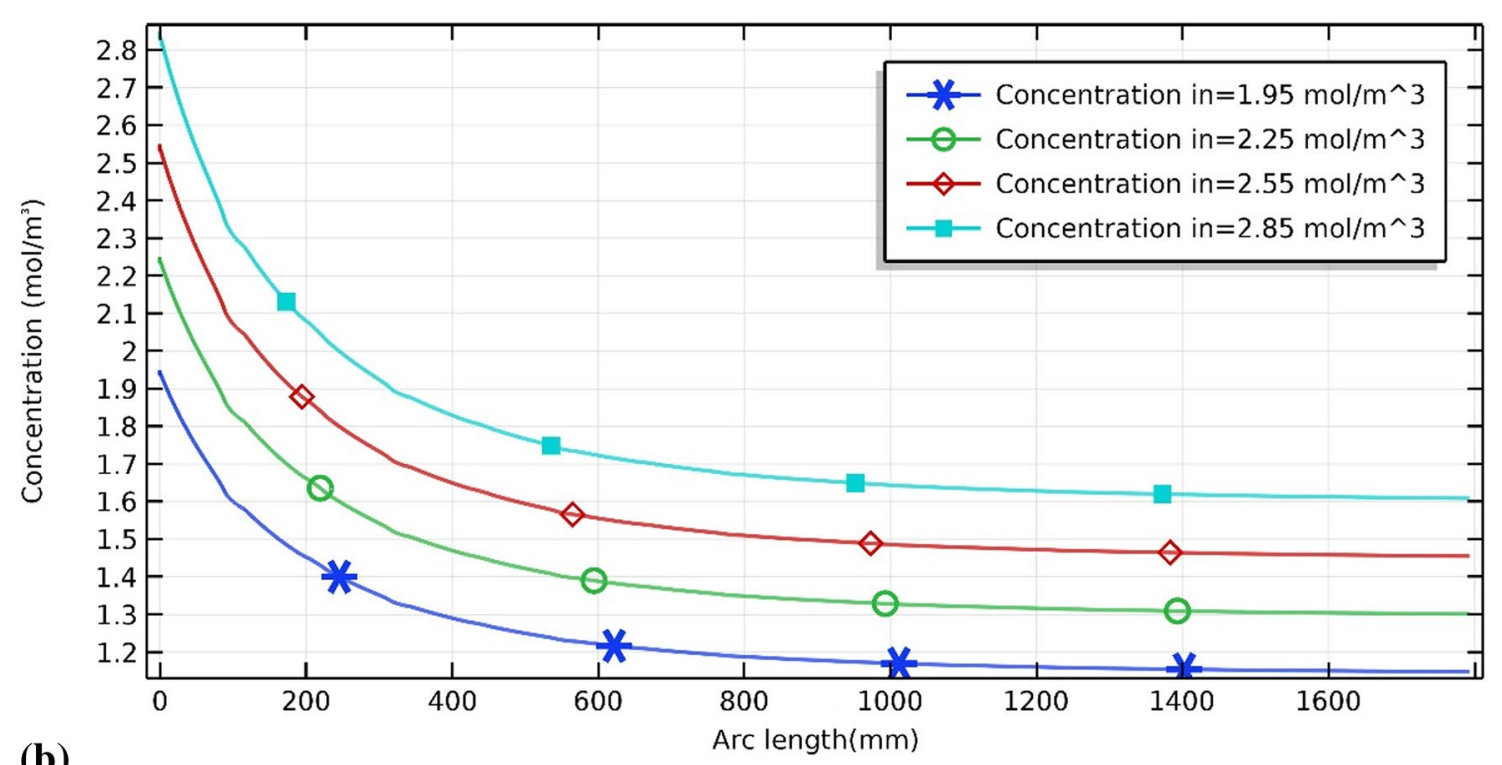

(b)

Fig. 11 Concentration of air outlet across the channel $\mathbf{a}$ and concentration variations along the membrane $\mathbf{b}$ for different concentrations

\section{Conclusion}

Recently, increasing attention has been paid to membranebased technology due to the fact that air dehumidification plays an important role in improving air quality and maintaining thermal comfort. Hence, membrane-based air dehumidification has been applied in ventilation and air conditioning. In this study, a conventional experimental design was developed to optimize the performance and structure of six samples of fabricated membranes for utilizing under diverse climatic conditions.

We conducted a series of polymeric porous membranes fabricated with different compositions that were prepared with various weight percentages of polysulfone (PSU), mixed with $N$-methyl-2-pyrrolidone (NMP) and dimethyl 
PSU-NMP-1,Flow rate $=60(\mathrm{~L} / \mathrm{h}), \mathrm{Rh}=79(\%)$

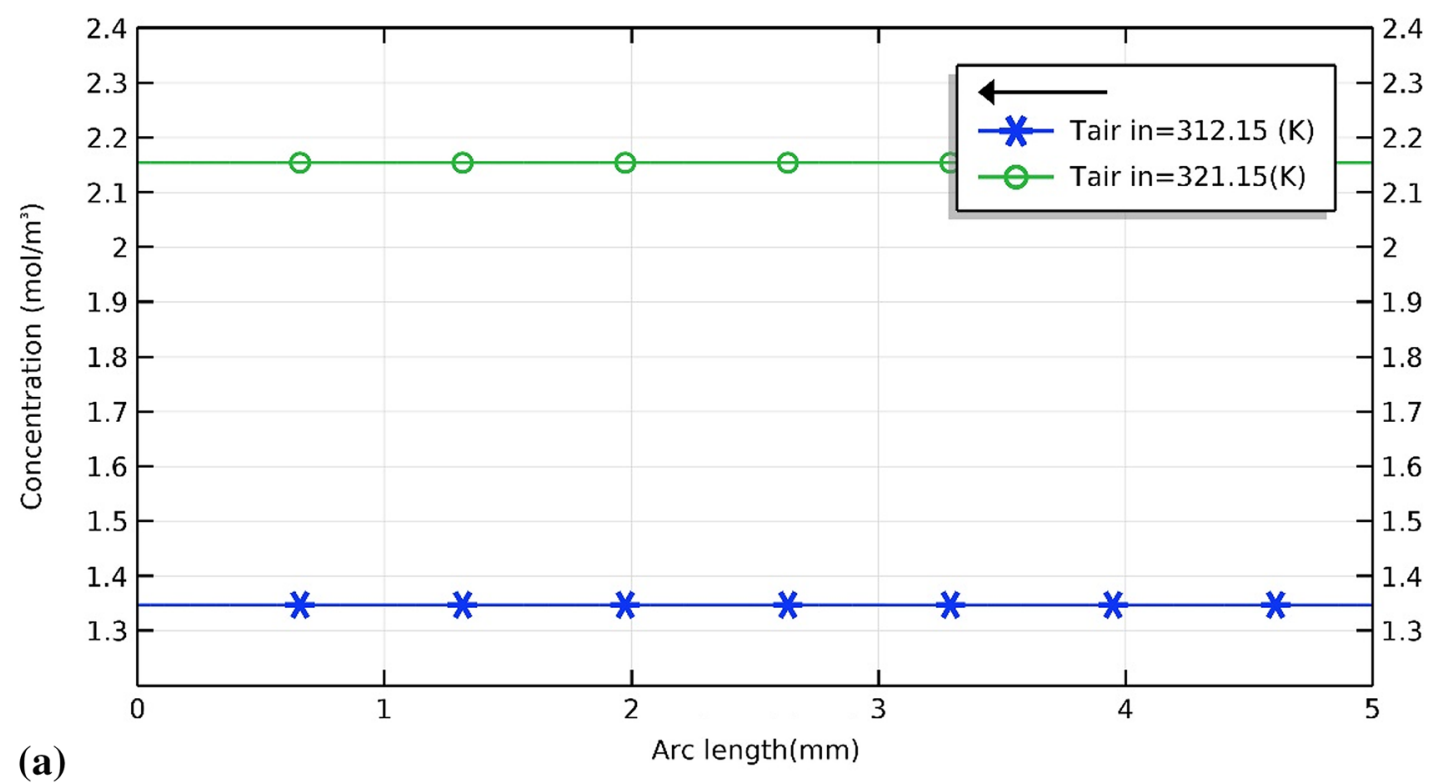

PSU-NMP-1,Flow rate $=60(\mathrm{~L} / \mathrm{h}), \mathrm{Rh}=79(\%)$

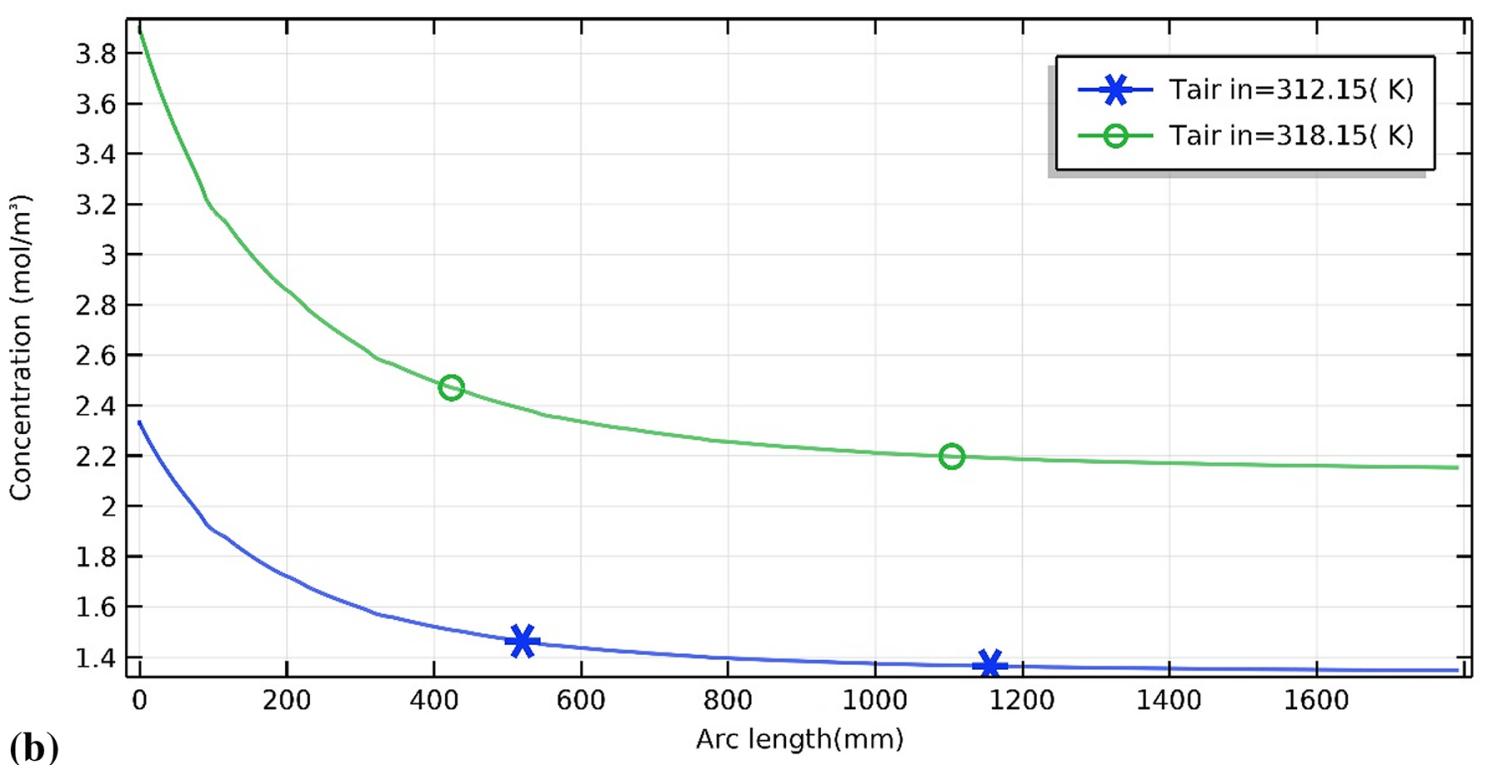

Fig. 12 Concentration of air outlet across the channel $\mathbf{a}$ and concentration variations along the membrane $\mathbf{b}$ for different temperatures

form amide (DMF) solvents. Additionally, the operating control factors such as flow rate, temperature, and humidity were controlled and optimized. Overall, the results indicate that the membranes with higher porosity are capable of dehumidifying the air to a higher extent. The selected membranes further demonstrated an improved performance in dry and humid areas with lower intake flow rates. Therefore, the fabricated membrane produces fresh cool air, and it can be applied as a guiding sample for designing the membrane-based dehumidifier with improved performance. 


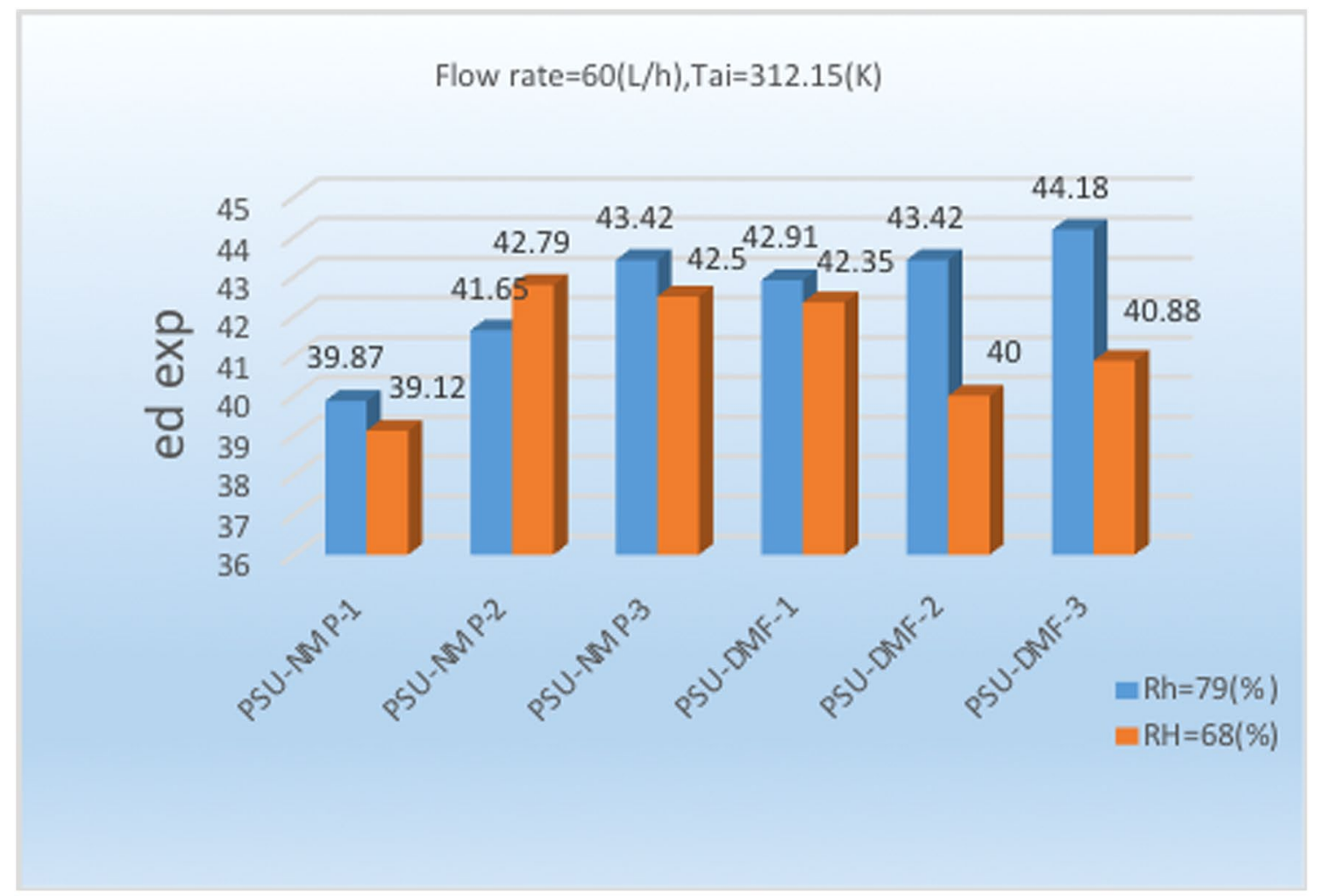

(a)

\section{Flow rate $=60(\mathrm{~L} / \mathrm{h}), \mathrm{Rh}=79(\%)$}

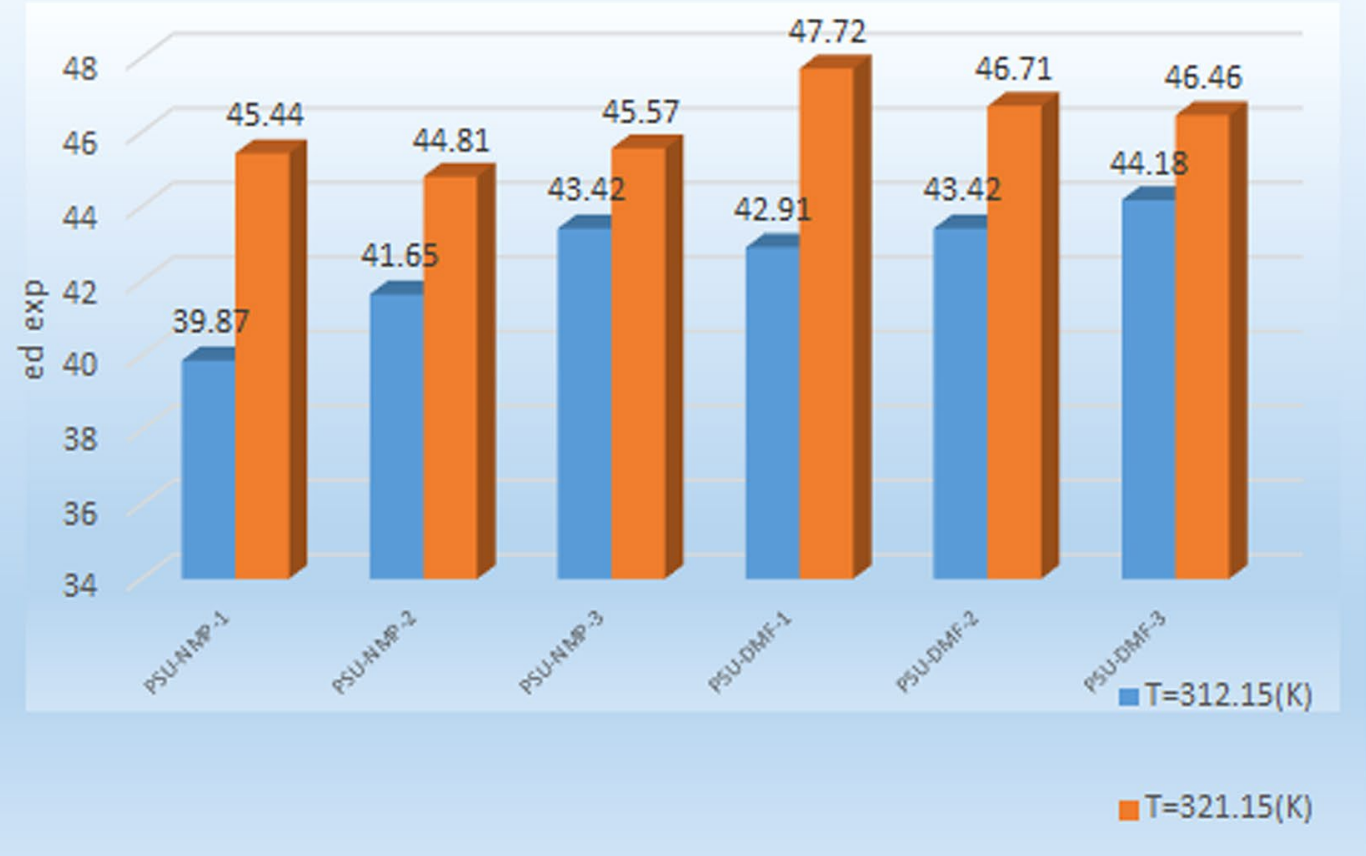

(b)

Fig. 13 Dehumidification efficiencies for different humidity levels (a) and different temperatures (b) 
Acknowledgements The authors would like to show their sincere gratitude to the Laboratory of "Catalyst and Chemical Engineering" at the University of Sharif for their support throughout the whole experiment. We would like to further acknowledge Professor Ahmad Tavasoli for his guidance and helpful suggestions.

Author contributions AMJ carried out the experimental work and developed the theory under the Supervision FF \& SAM and prepared the first Draft of the manuscript. All three authors contributed to the final version of the manuscript.

Open Access This article is distributed under the terms of the Creative Commons Attribution 4.0 International License (http://creativeco mmons.org/licenses/by/4.0/), which permits unrestricted use, distribution, and reproduction in any medium, provided you give appropriate credit to the original author(s) and the source, provide a link to the Creative Commons license, and indicate if changes were made.

\section{References}

1. Zhou, J., Zhang, X., Su, W., Sun, B.: Performance analysis of vacuum membrane distillation regenerator in liquid desiccant air conditioning system. Int. J. Refrig. 102, 112-121 (2019)

2. Liu, X., Qu, M., Liu, X., Wang, L.: Membrane-based liquid desiccant air dehumidification: a comprehensive review on materials, components, systems and performances. Renew. Sustain. Energy Rev. 110, 444-466 (2019)

3. Zhang, Z.-Y., Cao, X., Yang, Z., Shao, L.-L., Zhang, C.-L.: Modeling and experimental investigation of an advanced directexpansion outdoor air dehumidification system. Appl. Energy 242, 1600-1612 (2019)

4. Huang, S.-M., Luo, J.-C., Yang, M., Yuan, W.-Z., Hong, Y., Ye, W.-B.: Hexagonal parallel-plate air/liquid membrane contactor (HPMC) for liquid desiccant air dehumidification. Int. J. Refrig 100, 392-403 (2019)

5. Chai, S., Sun, X., Zhao, Y., Dai, Y.: Experimental investigation on a fresh air dehumidification system using heat pump with desiccant coated heat exchanger. Energy 171, 306-314 (2019)

6. Li, D., Qi, R., Zhang, L.-Z.: Performance improvement of electrolytic air dehumidification systems with high-water-uptake polymer electrolyte membranes. J. Appl. Polym. Sci. 136(26), 47676 (2019)

7. Zhang, L.-Z., Li, H., Qi, R.: Heat and mass transfer in PEMbased electrolytic air dehumidification element with an optimized anode-side electrochemical model. Int. J. Heat Mass Transf. 135, 1152-1166 (2019)

8. Ignat, M., Samoila, P., Cojocaru, C., Soreanu, G., Cretescu, I., Harabagiu, V.: Porous polymer/inorganic composite matrices as efficient desiccants for air dehumidification. Appl. Surf. Sci. 487, 1189-1197 (2019)

9. Song, X., Zhang, L., Zhang, X.: Analysis of the temperatures of heating and cooling sources and the air states in liquid desiccant dehumidification systems regenerated by return air. Energy $\mathbf{1 6 8}$, 651-661 (2019)

10. Rashidzadeh, M., Pourmahmoud, N., Simonson, C.J.: 3D computational fluid dynamics simulation of a 3-fluid liquid-to-air membrane energy exchanger (LAMEE). Appl. Therm. Eng. 153, 501-512 (2019)

11. Xu, H., Sun, X.Y., Dai, Y.J.: Thermodynamic study on an enhanced humidification-dehumidification solar desalination system with weakly compressed air and internal heat recovery. Energy Convers. Manag. 181, 68-79 (2019)
12. Chen, Q., Jones, J.R., Archer, R.H.: A dehumidification process with cascading desiccant wheels to produce air with dew point below $0{ }^{\circ} \mathrm{C}$. Appl. Therm. Eng. 148, 78-86 (2019)

13. Salimi, M., Balou, S., Kohansal, K., Babaei, K., Tavasoli, A., Andache, M.: Optimizing the preparation of Meso- and Microporous Canola Stalk-derived hydrothermal carbon via response surface methodology for Methylene Blue removal. Energy Fuels 31(11), 12327-12338 (2017)

14. Tavasoli, A., et al.: Influence of the blend nickel/porous hydrothermal carbon and cattle manure hydrochar catalyst on the hydrothermal gasification of cattle manure for $\mathrm{H}_{2}$ production. Energy Convers. Manag. 173, 15-28 (2018)

15. Salimi, M., Tavasoli, A., Balou, S., Hashemi, H., Kohansal, K.: Influence of promoted bimetallic Ni-based catalysts and micro/ mesopores carbonaceous supports for biomass hydrothermal conversion to H2-rich gas. Appl. Catal. B Environ. 239, 383-397 (2018)

16. Ghadikolaei, N.F., Balou, S., Moradi, A., Kowsari, E., Taromi, F.A.: Preparation of porous biomass-derived hydrothermal carbon modified with terminal amino hyperbranched polymer for prominent $\mathrm{Cr}(\mathrm{VI})$ removal from water. Bioresour. Technol. 288, 121545 (2019)

17. Qasem, N.A.A., Zubair, S.M.: Performance evaluation of a novel hybrid humidification-dehumidification (air-heated) system with an adsorption desalination system. Desalination 461, 37-54 (2019)

18. Fakharnezhad, A., Masoumi, S., Keshavarz, P.: Analysis of design parameter effects on gas dehumidification in hollow fiber membrane contactor: theoretical and experimental study. Sep. Purif. Technol. 226, 22-30 (2019)

19. Zhang, L., Zha, X., Song, X., Zhang, X.: Optimization analysis of a hybrid fresh air handling system based on evaporative cooling and condensation dehumidification. Energy Convers. Manag. 180, 83-93 (2019)

20. He, W.F., Chen, J.J., Zhen, M.R., Han, D.: Thermodynamic, economic analysis and optimization of a heat pump driven desalination system with open-air humidification dehumidification configurations. Energy 174, 768-778 (2019)

21. She, X., Chen, Y., Wang, Y., Wang, S., Luo, Y.: Molecular dynamics simulation on LiCl-H2O interfacial phenomenon for liquid desiccant dehumidification. Energy Proc. 158, 2106-2111 (2019)

22. Park, J.-Y., Dong, H.-W., Cho, H.-J., Jeong, J.-W.: Energy benefit of a cascade liquid desiccant dehumidification in a desiccant and evaporative cooling-assisted building air-conditioning system. Appl. Therm. Eng. 147, 291-301 (2019)

23. Scovazzo, P., MacNeill, R.: Membrane module design, construction, and testing for vacuum sweep dehumidification (VSD): Part I, prototype development and module design. J. Memb. Sci. 576, 96-107 (2019)

24. Zhi, J., Dong, C., Guo, M., Qi, R., Zhang, L.: Wettability and performance enhancement with durable super-hydrophilic surfaces for plastic liquid desiccant dehumidification systems. Energy Build. 187, 77-85 (2019)

25. Petukhov, D.I., et al.: Thin graphene oxide membranes for gas dehumidification. J. Memb. Sci. 577, 184-194 (2019)

26. Kabeel, A.E., Bassuoni, M.M.: Energy efficient moist free air conditioning system integrated with total heat desiccant solution system. Int. J. Refrig 100, 220-226 (2019)

27. Wang, X., Wang, L., Yin, X., Jiang, Y., Liu, H., Jia, L.: Modeling and performance analyses of a batch-wise liquid desiccant air conditioning system. Build. Environ. 154, 1-12 (2019)

28. Bai, H., Zhu, J., Chu, J., Chen, X., Cui, Y., Yan, Y.: Influences of the mixed $\mathrm{LiCl}-\mathrm{CaCl}_{2}$ liquid desiccant solution on a membranebased dehumidification system: parametric analysis and mixing ratio selection. Energy Build. 183, 592-606 (2019) 
29. Dong, C., Lu, L.: Enhancing the dehumidification efficiency of solar-assisted liquid desiccant air dehumidifiers using nanoscale $\mathrm{TiO}_{2}$ super-hydrophilic coating. Energy Proc. 158, 5765-5769 (2019)

30. Yang, Z., Tao, R., Ni, H., Zhong, K., Lian, Z.: Performance study of the internally-cooled ultrasonic atomization liquid desiccant dehumidification system. Energy 175, 745-757 (2019)

31. Jin, Z., Hafner, A., Eikevik, T.M., Nekså, P.: Preliminary study on $\mathrm{CO}_{2}$ transcritical ejector enhanced compressor refrigeration system for independent space cooling and dehumidification. Int. J. Refrig 100, 13-20 (2019)

32. Naik, B.K., Muthukumar, P.: Experimental investigation and parametric studies on structured packing chamber based liquid desiccant dehumidification and regeneration systems. Build. Environ. 149, 330-348 (2019)

33. Guo, Y., Al-Jubainawi, A., Peng, X.: Modelling and the feasibility study of a hybrid electrodialysis and thermal regeneration method for $\mathrm{LiCl}$ liquid desiccant dehumidification. Appl. Energy 239, 1014-1036 (2019)

34. Chu, J., Chen, Z., Bai, H., Zhu, J.: Experimental study of liquid to air membrane energy exchanger (LAMEE) performance by measuring its temperature fields. Therm. Sci. Eng. Prog. 10, 163-168 (2019)

35. Sun, B., Zhang, M., Huang, S., Su, W., Zhou, J., Zhang, X.: Performance evaluation on regeneration of high-salt solutions used in air conditioning systems by electrodialysis. J. Memb. Sci. 582, 224-235 (2019)

36. Cho, H.-J., Cheon, S.-Y., Jeong, J.-W.: Experimental analysis of dehumidification performance of counter and cross-flow liquid desiccant dehumidifiers. Appl. Therm. Eng. 150, 210-223 (2019)

37. Wen, T., Lu, L.: A review of correlations and enhancement approaches for heat and mass transfer in liquid desiccant dehumidification system. Appl. Energy 239, 757-784 (2019)

38. Li, G.-P., Qi, R., Zhang, L.-Z.: Performance study of a solarassisted hollow-fiber-membrane-based air humidification-dehumidification desalination system: effects of membrane properties. Chem. Eng. Sci. 206, 164-179 (2019)

39. Su, W., Li, H., Sun, B., Li, S., Zhang, X.: Performance investigation on a frost-free air source heat pump system employing liquid desiccant dehumidification and compressor-assisted regeneration based on exergy and exergoeconomic analysis. Energy Convers. Manag. 183, 167-181 (2019)

40. Vivekh, P., Bui, D.T., Wong, Y., Kumja, M., Chua, K.J.: Performance evaluation of PVA-LiCl coated heat exchangers for nextgeneration of energy-efficient dehumidification. Appl. Energy 237, 733-750 (2019)

Publisher's Note Springer Nature remains neutral with regard to jurisdictional claims in published maps and institutional affiliations. 